\title{
PICTURING THE NEWS:
}

THE INTELLECTUAL ARRANGEMENT AND DESCRIPTION

OF THE CHATHAM DAILY NEWS COLLECTION

\author{
by \\ Jessica Anne Glasgow, \\ BFA, Ryerson University, 2013
}

An applied thesis project

presented to Ryerson University

In partial fulfillment of the requirements for the degree of

Master of Arts

in the program of

Film and Photography Preservation

and Collections Management

Toronto, Ontario, Canada, 2015

(C) Jessica Glasgow 2015 
I hereby declare that I am the sole author of this thesis. This is a true copy of the thesis, including any required final revisions, as accepted by my examiners.

I authorize Ryerson University to lend this thesis to other institutions or individuals for the purpose of scholarly research.

I further authorize Ryerson University to reproduce this thesis by photocopying or by other means, in total or in part, at the request of other institutions or individuals for the purpose of scholarly research.

I understand that my thesis may be made electronically available to the public.

Jessica Anne Glasgow 
Picturing the News: The Intellectual Arrangement and Description of the Chatham Daily News Collection

Master of Arts, 2015

Jessica Anne Glasgow

Film and Photography Preservation and Collections Management

Ryerson University

\section{Abstract}

This thesis is an applied project in managing and preserving photographic press collections in museums and archives, focusing on the Chatham Daily News Collection at the Chatham-Kent Museum. The collection was donated by the Chatham Daily News to the museum in 1990 and consists of ca. 300,000 black and white negatives, ca. 10,000 black and white contact prints and 8 administrative record books from 1946 to 1987 . This thesis addresses the growing occurrence of press collections that are donated to museums and archives for preservation, and what these institutions can do to make them more accessible. The project was comprised of an inventory, a standardized finding aid and a detailed container list. Data from a representative sample of the collection was gathered and analyzed in order to better understand and describe the negatives and the role that photography played as a tool of communication at the Chatham Daily News. 


\section{Acknowledgements}

This thesis has been an incredible undertaking, and would not have been possible without the support, wisdom and assistance of the following people:

My first reader, Thierry Gervais, for his expertise on photographs and the press and for generously dedicating his time and assistance during the conception, writing and editing of this thesis.

My second reader, Alison Skyrme, for sharing her valuable time and effort in editing this document and providing guidance during the creation of the finding aid.

The staff at the Chatham-Kent Museum - Stephanie, Lydia and Deanna, who were always so welcoming and accommodated my every inquiry and need.

My parents, to whom I am so thankful to for instilling in me a strong work ethic and who are always there to comfort and encourage me.

Finally, my fiancé, Dustin, who has been an incredible source of support and encouragement. 


\section{Table of Contents}

1. Introduction 1

2. Literature Review 6

a. Archival Arrangement and Description 6

b. Contextual Research 9

$\begin{array}{ll}\text { 3. Methodology } & 15\end{array}$

$\begin{array}{ll}\text { a. Historical Context } & 16\end{array}$

b. Intellectual Arrangement and Description 20

c. Representative Sample: Overview 26

d. Representative Sample: Findings 27

4. Conclusion 40

Appendix I: Finding Aid 43

Appendix 2: Container List 56

Bibliography $\quad 65$ 


\section{List of Figures}

All photographs are courtesy of the Chatham-Kent Museum. All photographs taken by staff photographers of the Chatham Daily News, unless otherwise stated. Descriptive titles were assigned by the author of this thesis.

Figure 1: CDN promotional display, cellulose acetate negative, 4" $x$ 5," June 1954,

Photographer Unknown

Figure 2: Boy on bicycle with CDN, cellulose acetate negative, 4"x 5," June 1964,

Photographer Unknown

Figure 3: Housing of negatives, digital photograph, December 2014, Jessica Glasgow 25

Figure 4: Housing of negatives, digital photograph, December 2014, Jessica Glasgow 25

Figure 5: Source of Images in Newspaper: Chatham Daily News vs. Press Agencies 29

Figure 6: Number of photos produced by Chatham Daily News Staff per Year 30

Figure 7: Subject Matter of Photographs in the Chatham Daily News Collection 31

Figure 8: "Heat Fails to Stop 'Cramming'" Series, cellulose acetate negatives, 4"x5", 33 July $11^{\text {th }}, 1947$, Photographer Unknown

Figure 9: Page 11, CDN, newsprint, $60 \mathrm{~cm} \times 37.5 \mathrm{~cm}$ June $11^{\text {th }}, 1947$

Figure 10: CDN Advertisement, newsprint, $7 \mathrm{~cm} \times 9 \mathrm{~cm}, 1958$

Figure 11: Students in classroom, cellulose acetate negative, 4"x 5," 1946, 37 Photographer Unknown

Figure 12: Marching band, cellulose acetate negative, 4"x 5," 1946, Photographer 38 Unknown

Figure 13: Crowd watching race, cellulose acetate negative, 4" $x$ 5," 1951, Photographer Unknown

Figure 14: Boys with calf, cellulose acetate negative, 4"x 5," 1954, Photographer Unknown 45

Figure 15: Newlyweds cut cake, cellulose acetate negative, 4"x 5," 1946,

Photographer Unknown

Figure 16: Portrait of elderly man, cellulose acetate negatives, $54 \mathrm{~mm} \times 35 \mathrm{~mm}, 1987$, Photographer Unknown

Figure 17: Boy skateboarding, cellulose acetate negatives, $54 \mathrm{~mm} \times 35 \mathrm{~mm}, 1987$,

Photographer Unknown

Figure 18: Teens at formal dance, cellulose acetate negatives, $54 \mathrm{~mm} \times 35 \mathrm{~mm}, 1987$,

Photographer Unknown

Figure 19: Condition of collection, digital photograph, December 2014, Jessica Glasgow 50

Figure 20: Condition of collection, digital photograph, December 2014, Jessica Glasgow 50

Figure 21: Condition of collection, digital photograph, December 2014, Jessica Glasgow 50 


\section{Introduction}

Daily newspapers, such as the Chatham Daily News (CDN) have played a significant role in building community identities by disseminating news pertaining to a very specific geographic area. As described by G.P. de T. Glazebrook, "a quite small town might have two or three newspapers and each would bear the personal imprint of the editor."1 By capturing the day-to-day life and people of the area, the CDN created a portrait of the community that could be shared and preserved through the newspaper's publication. Small community newspapers like the CDN often printed content that reflected the knowledge of

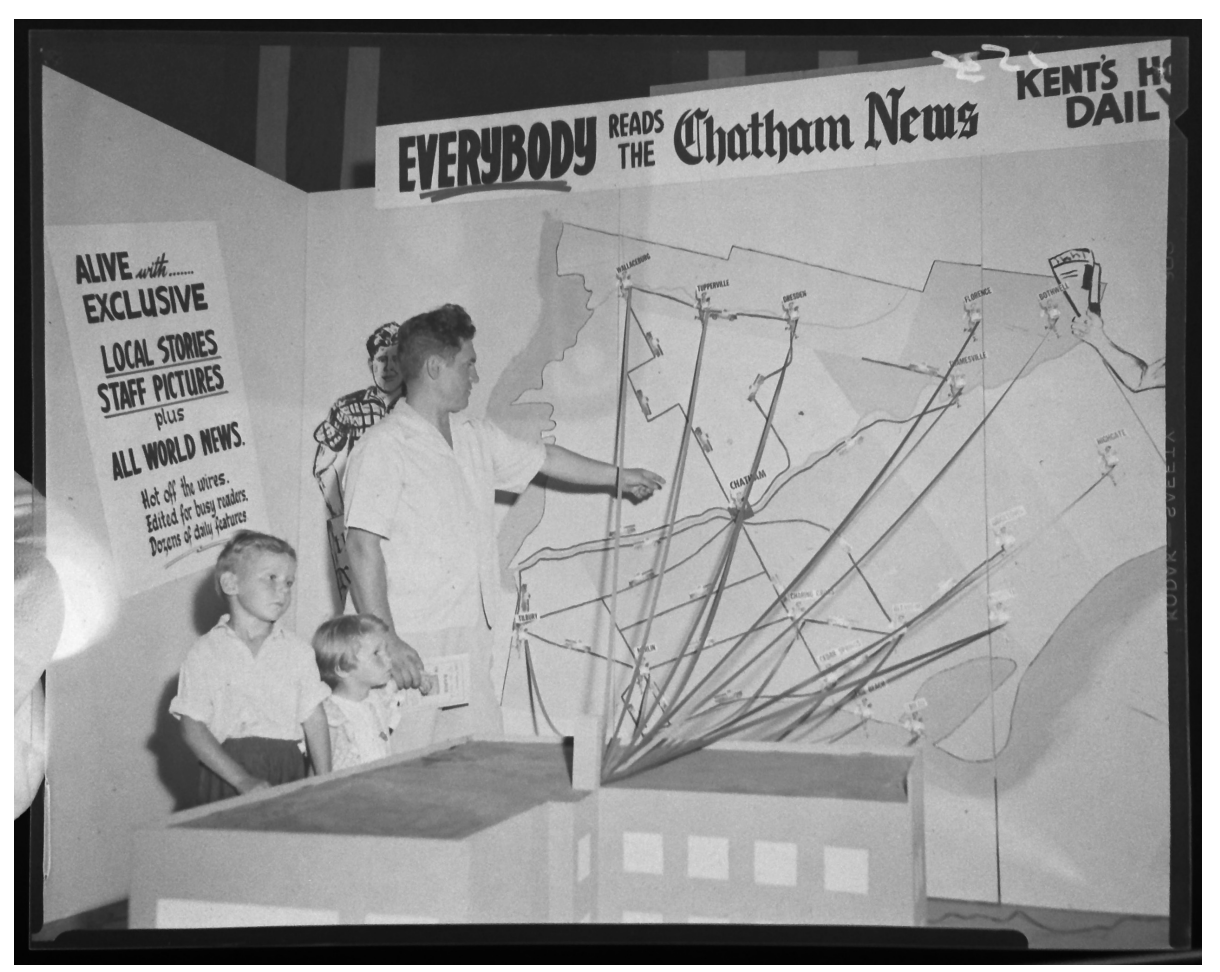

Figure 1: Photographer Unknown. A photograph from the collection showing a promotional display for the CDN, June 1954. Cellulose acetate negative, 4" $\times 5$," Chatham Daily News Collection, Chatham-Kent Museum.

${ }^{1}$ G. P. De T. Glazebrook, Life in Ontario: A Social History, (1975) 241. 
its owners, editors, writers and photographers and their relationship to the area and its people. The CDN used photographs to disperse information by providing the reader with a visual account of the news. These photographs, often viewed before the text was read, allowed readers in small towns to identify the familiar people and places that they depicted, encouraging them to participate in the building of a community identity.

The presence of photographs in newsprint has been an accepted practice since the halftone process was introduced at the end of the ninetheenth century. ${ }^{2}$ As Jason E. Hill and Vanessa R. Schwartz explain in their introduction to Getting the Picture: The Visual Culture of the News, the news picture is "an important means of communication and information. ${ }^{3}$ However, as they demonstrate, histories of the news and press have yet to account for the role that the photograph has played. ${ }^{4}$ Press photographs, as they note, have an "instrumental and timely" purpose, and have the tendency to be forgotten after they fulfill this immediate purpose. ${ }^{5}$ It is becoming increasingly common for newspapers and press agencies to donate their obsolete analogue photographic collections to museums and archives for preservation and

\footnotetext{
2 Bodo Von Dewitz, , ed. Kiosk: A History of Photojournalism, 1839-1973, (2001) 40.

3 Jason E. Hill and Vanessa R. Schwartz, eds. Getting the Picture: The Visual Culture of the News, (2015), 5.

${ }^{4}$ Ibid., 3.

${ }^{5}$ Ibid., 5.
} 
research, ${ }^{6}$ where the original context is often lost in the transition from an immediate tool of communication to a museum object.

This thesis focuses on such a collection: the Chatham Daily News Collection housed by the Chatham-Kent Museum (Chatham, Ontario). This collection consists of approximately 300,000 black and white photographic acetate negatives taken by staff photographers and approximately 10,000 black and white contact prints made at the CDN between 1946 and 1987. The collection also contains eight ledger books for the years: 1975 , and 1977 to 1983. These ledger books contain daily notes (presumably written by the editor) pertaining to which stories needed to be covered, what photographs needed to be taken, and which staff member would cover each event.

Since the CDN donated the collection to the Chatham Museum in 1990, ${ }^{7}$ it has remained untouched by museum staff. Due to the large size of the collection and the small number of staff at the museum, there are currently no catalogue or database records for this collection, and it has not been digitized or disseminated online. It was noted by museum staff that access to the collection has been limited over the years due to the lack of organization and access points, despite the frequent research requests they receive.

\footnotetext{
${ }^{6}$ Mary Panzer. "The Meaning of the Twentieth-Century Press Archive," (2011), 49.

${ }^{7}$ Donation agreement, December 8, 1990.
} 
The main consideration of this thesis was how can access to this collection be improved so that it can be more efficiently managed by museum staff, and provide researchers with a better understanding of its contextual history? In order to answer this question, this thesis has two aims: the first is to improve access to this collection through intellectual organization and description in the creation of a finding aid; the second is to enrich the collection by describing the content and context of the collection through research and the examination of a representative sample of the collection. In addition to intellectually arranging and describing these objects, it was important to consider and describe their use and value at the time and place in which they were produced.

The following paper outlines the historical context of this collection by examining literature on the history of photojournalism, the press in Canada, the history of Chatham-Kent, as well as manuals for archival arrangement and description. It also demonstrates the methods and standards used in the creation of the finding aid and the representative sample. Lastly, it includes various illustrations of the collection and the finding aid itself.

The frequent research requests to access this collection demonstrate that the CDN is still significant to the community of Chatham-Kent. These materials are not only being requested as evidence of specific news stories or events, but as a portal for people in Chatham-Kent to learn more about the people and 
places of the past. This thesis questions: Was the purpose of these photographs to capture and preserve the essence of the community, and can this responsibility be passed on to the museum by creating access to this collection? 


\section{Literature Survey}

This literature survey examines available textual resources regarding the creation of archival finding aids and provides an historical context for the Chatham Daily News Collection at the Chatham-Kent Museum. The survey is divided into two sections: the archival arrangement and description of photographic collections and the various aspects and standards used for creating a finding aid; and the historical context of this collection, including the history of photojournalism and newspapers in Canada, as well as local history.

\section{a. Archival Arrangement and Description}

The largest part of this project consisted of surveying the collection and creating an archival finding aid to increase user access and improve physical and intellectual control by the museum staff. During this process it was important to understand the various elements and standards used in Canadian institutions in order to create a finding aid that will be relevant and accurate to future users.

The main standards manuals consulted during this project were the Canadian Archival Standards Rules for Archival Description ${ }^{8}$ (2008) prepared by

\footnotetext{
${ }^{8}$ Canadian Archival Standard Rules for Archival Description. Ottawa: Bureau of Canadian Archivists, 2008.
} 
the Bureau of Canadian Archivists and Describing Archives: A Content Standard ${ }^{9}$ (2013) written by the Society of American Archivists. Both of these manuals were used during the creation of the finding aid to ensure that it can be used efficiently by museum staff and researchers and can be shared with other institutions. Organizing Archival Records: A Practical Method of Arrangement and Description for Small Archives ${ }^{10}$ written by Georgia Department of Archives and History director David Carmicheal, is a book specifically tailored to smaller institutions whose employees and volunteers may not have formal training in archival practices. Carmicheal's goal is to provide tools that can be applied by anyone, no matter their education or the size or resources of the institution. This text clearly demonstrates how to arrange and describe a collection and gives basic instructions and templates for creating a finding aid. It was relevant to this practical project because it demonstrated how to go beyond the quantitative data included in the finding aid by creating additional access points for users. In the text Introduction to Vocabularies: Enhancing Access to Cultural Heritage, ${ }^{11}$ Elisa Lanzi and Howard Besser describe how the strong use of controlled vocabularies of image collections is key to making cultural heritage

\footnotetext{
9 Steven L. Hensen, Describing Archives: A Content Standard. 2nd ed., (2013).

10 David W. Carmichael, Organizing Archival Records, (2012).

${ }^{11}$ Elisa Lanzi, and Howard Besser, Introduction to Vocabularies: Enhancing Access to Cultural Heritage Information, (1998).
} 
available to the public. More importantly, they outline the existing standards and forms of vocabularies that will need to be followed during the creation of the finding aid and series-level descriptions of the Chatham Daily News Collection.

Two previous Master's theses by Film and Photography Preservation and Collections Management students focused on similar photographic press collections and methods of increasing user access. The 2012 paper "Finding Wolff: Intellectually Arranging the Werner Wolff Fonds at the Ryerson Image Centre" 12 by Sara Manco consisted of the intellectual arrangement of the Werner Wolff fonds at the Ryerson Image Centre and the creation of a finding aid. Manco's thesis provided an overview of the steps involved in the process of intellectually arranging a photographic collection of press photographs. However, this project differs because the finding aid was completed based on the original order of the collection, as opposed to Manco who imposed an intellectual order on the fonds. "Issues in Object-Level Description of Press Photography Collections: Toward A Metadata Standard for Photojournalism"13 written by Matthew Rushworth in 2012 highlighted the importance of object description and vocabulary as press collections move from their original

\footnotetext{
12 Sara L. Manco, "Finding Wolff: Intellectually Arranging the Werner Wolff Fonds at the Ryerson Image Centre," (2012).

13 Matthew Rushworth, "Issues In Object-Level Description of Press Photography Collections: Toward A Metadata Standard For Photojournalism," (2012).
} 
agencies to cultural heritage institutions in order to preserve any original context. Both of these theses were relevant to this project because they also worked towards increasing access to photographic press collections by describing the subjects of the photographs. This project aims to make research easier and to enrich the descriptions by making qualitative generalizations about the collection instead of just providing quantitative data in the finding aid.

\section{b. Contextual Research}

Historian Mary Panzer provides a context for modern photojournalism since 1955 in Things As They Are (2005). ${ }^{14}$ Panzer uses photographic stories as they were originally published to emphasize the role of many different agency authors in their creation. While this publication focuses on the photographic essay as opposed to single pictures like those in the CDN Collection, it is a reminder of the many elements that come into play in a news agency. KIOSK: A History of Photojournalism 1839-1973'15 released in 2001 by Bodo von Dewitz and Robert Lebeck examines layouts of illustrated magazines. Similar to Panzer's Things As They Are, Lebeck and von Dewitz explore the creation of

\footnotetext{
${ }^{14}$ Mary Panzer, Things As They Are: Photojournalism in Context Since 1955, (2005).

15 Bodo von Dewitz, ed., Robert Lebeck, comp., Kiosk: A History of Photojournalism, 1839-1973, (2001).
} 
photographic reports by examining the finished layouts as they were seen by readers. Getting the Picture: The Visual Culture of the News ${ }^{16}(2015)$ is a recently released collection of essays compiled by Jason E. Hill and Vanessa R. Schwartz that specifically examine the role that photographs and other visual media have played in the press from its invention to the present day. During the arrangement and description process, these works were a reminder to consider the original purpose and value of the CDN Collection and what contextual information may have been lost during its transfer to the museum. These recent sources on the history of photojournalism indicate that scholars are moving away from a generalized history of photojournalism, towards specific, corpus-based research that emphasizes the original context and life span of press photographs.

Canadian Newspapers: The Record of our Past, The Mirror of our Time, ${ }^{17}$ edited by academic librarian Hana Komorous, is a written account of the proceedings of the Second National Newspapers Colloquium that took place in Vancouver, B.C. in 1987. It highlights the importance of the collection, preservation and access to Canadian newspapers such as the CDN. The keynote

\footnotetext{
16 Jason E. Hill and Vanessa R. Schwartz, eds., Getting the Picture: The Visual Culture of the News, (2015).

17 Hana Komorous, Canadian Newspapers: The Record of Our Past, The Mirror of Our Time: Proceedings of the Second National Newspapers Colloquium, Vancouver, British Columbia, June 11,1987, (1989).
} 
address by Marianne Scott notes that newspapers are the most unique and diversified publishing activities in Canada because of their geographically focused production and distribution, high print numbers, and intrinsically short lifespan. ${ }^{18}$ Scott also points out that the preservation of newspapers are problematic for museums and archives due to their overwhelming number and short life expectancy. ${ }^{19}$ Although this work is focused on newspapers and not the photographs featured in them, it emphasizes the importance of preserving Canadian press collections for the future as a unique representation of Canadian history, and the inherent issues with trying to preserve something that is specifically created to be immediate and disposable.

The 1990 book The Rise of the Canadian Newspaper, ${ }^{20}$ by literary editor and writer Douglas Fetherling, outlines the social history and development of newspapers in Canada. He provides the context of publication for daily papers and highlights the growing trend of larger metropolitan newspaper companies overtaking modest papers in smaller areas such as Chatham. This analysis helped to clarify the current organization of the Chatham Daily News and why the collection may have been donated to the museum. A History of Journalism

\footnotetext{
18 Ibid., vii.

19 lbid.

20 Douglas Fetherling, The Rise of the Canadian Newspaper, (1990).
} 
in Canada ${ }^{21}$ is an older but thorough publication written by Wilfred Kesterton in 1967. In the fourth chapter, entitled "The Fourth Press Period: Mutation, 1900 to $1967, "$ he outlines many of the factors that changed the press industry during this period such as World Wars I and II, and rapidly changing technological and industrial advancements that created new forms of communication and distribution of information. These are just several aspects of the early twentieth century that modified the Canadian press into the system that was in place when this collection was created. This source provides a cultural and social context for the photographs in the CDN Collection.

In "The Meaning of the Twentieth-Century Press Archive," Mary Panzer highlights the increasing movement of obsolete photographic collections from press agencies to institutions such as art museums, archives and research centers in order to be preserved and accessed. ${ }^{22}$ Panzer also notes that information can be lost as collections are removed from their original context and given new meaning by the receiving institution, ${ }^{23}$ a phenomena especially relevant to the CDN Collection. This source is a reminder that, while many press collections are donated to museums with the good intentions of preservation and greater public access, unless they are supported by materials that help to

\footnotetext{
${ }^{21}$ Wilfred H. Kesterton, A History of Journalism in Canada, (1967).

22 Mary Panzer, " Twentieth-Century Press Archive," (2011), 46.

23 Ibid., 49.
} 
enhance and explain their original context, press collections in museums will remain misunderstood and under-used.

Finally, several publications focusing on Chatham-Kent were consulted in order to gather more background information on the Chatham Daily News and the role the publication played in the area. G.P. de T. Glazebrook briefly discusses the role of newspapers in early nineteenth century Ontario in his 1975 book Life in Ontario: A Social History. ${ }^{24}$ Glazebrook analyzes how small community papers at this time were very much reflective of their owners', editors' and writers' beliefs and opinions, indicating that the newspapers were as much a portrait of their owners as they were of the area that they served. Romantic Kent: The Story of a County $1626-1952,{ }^{25}$ written in 1952 by former journalist and editor of the Chatham Daily News Victor Lauriston, chronicles the history of the county, including an account of the development of the CDN. Both of these sources build a very specific local context for this collection and will help create connections to other materials in the museum's holdings.

The publications discussed in this section help to provide an historical context for the CDN Collection. Most importantly, they highlight that access to

\footnotetext{
${ }^{24}$ G. P. De T. Glazebrook, Life in Ontario: A Social History, (1975).

25 Victor Lauriston, Romantic Kent: The Story of a County 1626-1952, (1952).
} 
press collections within institutions such as museums is often limited because the original context of the photographs is not properly understood or described.

\section{Conclusion}

The results of this literature survey demonstrate that, while there are sufficient and recent resources concerning photojournalism, there are significantly less sources that focus on the history of newspapers and photojournalism in Canada. There is also little literature concerning press collections held in museums and archives or how to use a tailored approach to these types of collections. Until the publication of books like KIOSK and Things As They Are, histories of photojournalism have largely ignored the final destination of photographs: the published layout. Current research in the field is moving towards a focus on large corpuses in order to reveal the process, intention and consumption of image-making and publishing in the press. This thesis will contribute to this growing research trend because press collections are increasingly being made available to the public through museums and archives, but contextual information such as their organizational structure, administrative history and original use is rarely provided to users. It is my hope that this project will add to the efforts of Rushworth and Manco in revisiting traditional methods of arrangement and description to find a way to describe press collections and increase access and research potential. 


\section{Methodology}

This thesis began with a request from the staff of the Chatham-Kent Museum to help improve access to the Chatham Daily News Collection. The collection, containing approximately 300,000 photographic negatives, 10,000 contact prints and eight ledger books was donated by the CDN to the ChathamKent Museum in $1990 .{ }^{26}$ The collection was donated to the museum because the CDN did not have the space to continue to store it and wanted to ensure that it would be archived and made accessible to the general public. ${ }^{27}$ As Hill and Schwartz note, the production of physical newspapers slowed at the beginning of the twenty-first century and many photography departments became smaller or disappeared altogether. ${ }^{28}$ In the case of the $C D N$, there was simply neither the room nor the staff available to archive the negatives for future reference.

In a letter written prior to the donation of the collection, the museum curator promised the editor of the CDN that they would provide accessibility to the collection to the best of their ability and would begin organizing and cataloguing the photographs as soon as possible..$^{29}$ Twenty-five years later, the full-time museum staff have been unable to increase access to the collection and

\footnotetext{
${ }^{26}$ Donation agreement, December 8, 1990.

27 Diana Martin (Photographer, CDN), e-mail message to author, May 15, 2015.

28 Jason E. Hill and Vanessa R. Schwartz, Getting the Picture: The Visual Culture of the News, (2015), 209.

${ }^{29}$ Chatham-Kent Museum Curator, letter to Editor of Chatham Daily News, November $14^{\text {th }}$, 1990.
} 
still receive frequent research requests. Due to the large size of the collection and the small number of staff at the museum, there are currently no catalogue or database records for this collection, and it has not been inventoried, digitized or disseminated online.

The first step in improving access was to examine the historical context of this collection and explore the original purpose of the negatives at the time they were created. The collection was then inventoried, intellectually ordered and described in an archival finding aid. The enormity of the collection and limited time frame made it difficult to describe it in definite terms within the finding aid. In order to get a more detailed view of the content of the negatives and what purpose they served within the $C D N$, data was collected and analyzed from a representative sample of the collection.

\section{a. Historical Context}

The process of description began by researching the entity that created the objects in the collection - the Chatham Daily News. In addition to speaking with the $C D N$, museum records, local history books and issues of the newspaper on microfilm were also consulted.

The CDN is a daily newspaper that serves the city of Chatham and surrounding areas. Located in South-western Ontario, Chatham-Kent is primarily 
an agricultural and industrial area home to approximately 103,000 residents. ${ }^{30} \mathrm{It}$ was the site of the historic Battle of the Thames during the war of 1812 and is also home to the Dawn Settlement, a community started by Josiah Henson, a major figure in the Underground Railroad and the main character of Harriet Beecher Stowe's novel, Uncle Tom's Cabin. ${ }^{31}$ Chatham is also home to one of the earliest automobile manufacturers in Canada, Gray-Dort Motors Ltd., and the world's largest vintage automobile auction and restoration house, RM Classic Cars. Among notable citizens are author Robertson Davies, championship figure skater Shae-Lynn Bourne, NHL hockey player for the Calgary Flames T.J. Brodie, and baseball player Fergie Jenkins.

The areas first newspaper was the Chatham Journal, which was in print from 1841 to 1844 . The Chatham Planet (predecessor to the CDN) was published weekly from 1857 to 1891, after which it became the Chatham Daily Planet until December 29th $1922 .^{32}$ The Chatham Daily Planet and Banner-News merged to create the Chatham Daily News, whose headquarters were originally located at 45 Fourth Street and are presently located at 138 King Street West.

\footnotetext{
30 Statistics Canada. Chatham-Kent, Ontario (Code 3536020) and Chatham-Kent, Ontario (Code 3536) (table). Census Profile. 2011 Census. Statistics Canada Catalogue no. 98-316-XWE.

Ottawa. Released October 24, 2012. http://www12.statcan.gc.ca/census-recensement/2011/dp$\mathrm{pd} /$ prof/index.cfm?Lang $=\mathrm{E}$

${ }^{31}$ Harriet Beecher Stowe. Uncle Tom's Cabin or, Life Among the Lowly, (1852).

32 Jim and Lisa Gilbert, "Times May Change, but Some Issues Do Not." Chatham Daily News, July 13, 2012, Life sec. Accessed March 19, 2015.
} 
In 1946 the CDN claimed to be "First with the News" as "The Home Paper for South-western Ontario. "33 It featured sections such as World Affairs, Weather, the Voice of the People, Sports Spots, Farmers Markets and Classifieds, With the Women, and tidbits like the Daily Recipe and Flashbacks: From the Files of the News. A 1946 issue notes the CDN's association with the Canadian Press: "The news, with which is amalgamated the Daily Planet, is published each afternoon (Sundays and legal holidays excepted) by the Chatham Daily News Limited. Member of the Canadian press and the Andis Bureau of Circulation. The Canadian press is exclusively entitled to the use for republication of all news dispatched in this newspaper credited to it or to the Associated Press or Reuters and also the Local News published therein. ${ }^{34}$ By 1948 the Chatham Daily News claimed to be printing 300,000 issues per month (or approx. 11,538 copies per day). ${ }^{35}$ In 1953, an issue sold for five cents, and by 1958, it claimed to be "The only paper devoted exclusively to developing Kent" and was the source of "News for busy readers." ${ }^{36}$

\footnotetext{
33 Chatham Daily News, June 13, 1946, 1.

${ }^{34}$ Chatham Daily News, June 13, 1946, 4.

35 Chatham Daily News, June 9, 1948, 17.

${ }^{36}$ Chatham Daily News, June 13, 1958, 1.
} 
Today the CDN is currently owned by Canoe Sun Media Community

Newspapers, who are the publishers of eight newspapers across Chatham-Kent: the Chatham Daily News, the Citizen, Home Hunting Guide, Smart Shopper, Chatham This Week, Today's Farmer, Wallaceburg Courier Press and the Leader Spirit. Sun Media also delivers 45 million flyers each year, locally and nationally. Its distribution consists of $300+$ carriers and drivers, and has an average daily print run of 6,280 issues. ${ }^{37}$

In 1969 a one-year daily subscription in Kent County cost $\$ 17$ for same day delivery, ${ }^{38}$ which would equal approximately $\$ 109$ today ${ }^{39}$ However, the

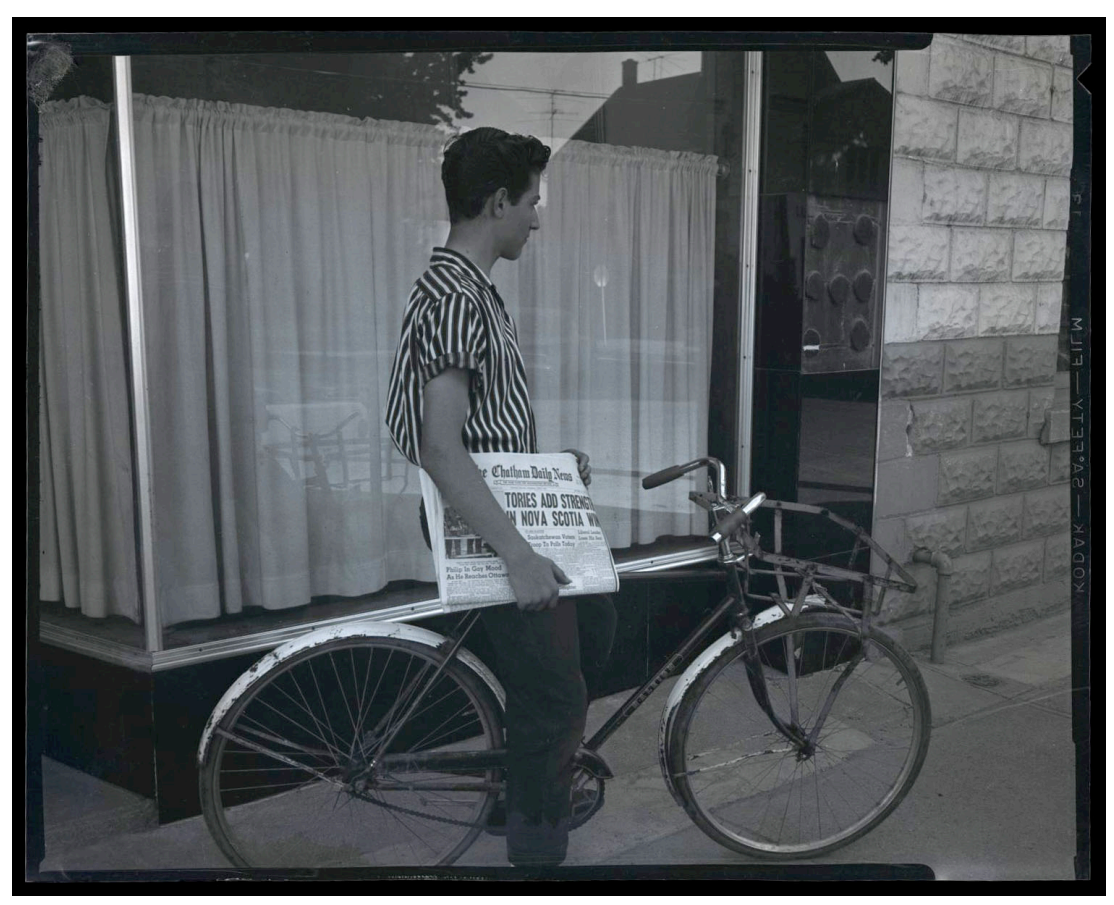

Figure 2: Photographer Unknown. A photograph from the collection showing a boy on his bicycle holding a copy of the CDN, June 1964. Cellulose acetate negative, 4 " $\times 5$," Chatham Daily News Collection, ChathamKent Museum.

\footnotetext{
37 Newspapers Canada, "2013 Daily Newspaper Circulation Report." (May 1, 2014.) Accessed March 17, 2015. http://www.newspaperscanada.ca/sites/default/files/2013 Daily Newspapers Circulation Report FINAL.pdf, Page 1.

38 Chatham Daily News, June 11, 1969, 1.

${ }^{39}$ Calculation based on $547 \%$ inflation rate over 46 years.
} 
subscription has doubled in cost since 1969; a one-year daily subscription to the CDN now (2015) costs $\$ 232.92$. Comparably, the London Free Press prints an average of 78,163 copies daily and a one-year subscription with delivery costs $\$ 274.58,{ }^{40}$ and the Toronto Star prints an average of 360,515 copies daily with a yearly subscription and delivery cost of $\$ 649.80 .{ }^{41}$ These numbers show that compared to the circulation of well-known newspapers in Southwestern Ontario, the $C D N$ has a relatively small circulation and is economically priced. In terms of cost, the CDN has always been affordable for the average family. In 1969 a oneyear subscription would have only cost approximately 19 cents per issue. Today, a subscription is still very affordable at $\$ 1.50$ per issue with a one-year subscription. These subscription prices further demonstrate that the role of the CDN was to provide the news and make it easily accessible to the community.

\section{b. Intellectual Arrangement and Description}

The next step in creating access to this collection after building context was to arrange and describe the contents so that the museum staff could assert physical and intellectual control over the collection. Describing Archives: A Content Standard (DACS) identifies arrangement as "the intellectual and or

\footnotetext{
40 Newspapers Canada, "2013 Daily Newspaper Circulation Report," 2.

41 Ibid., 2.
} 
physical processes of organizing documents" 42 and description as "the creation of an accurate representation of the archival material by the process of capturing, collating, analyzing and organizing information that serves to identify archival material and to explain the context..." ${ }^{43}$ This process began by examining the collection and creating an inventory of the existing physical arrangement and the content. The inventory consisted of recording the date range and location of each box of negatives, as well as recording how many sleeves they contained, and what was recorded on each sleeve.

Throughout the inventory and research process, museum staff as well as current staff at the CDN were consulted to determine if the existing arrangement matched the original order that the collection was in at the CDN. A note from 1994 outlines the costs invested in the CDN collection by the Museum, including 180 acid-free boxes and 1800 envelopes, indicating that the negatives were moved from the original 125 boxes to the new 180 boxes shortly after arrival at the museum. Museum records do not show why or how the negatives were moved from these original boxes, however it is likely that the larger boxes that were used for transport from the CDN were not archival or suited to the storage and retrieval standards of the museum.

\footnotetext{
42 Steven L. Hensen, Describing Archives: A Content Standard, (2013), xvii.

43 Ibid.
} 
The negatives are still arranged in chronological order and there is no record of any changes to the physical order during this movement. According to current CDN staff, this chronological storage matches the manner in which negatives are still stored at the CDN today; negatives are stored in a paper sleeve with the date written on them, and the sleeves are stored in chronological order from oldest to most recent. ${ }^{44}$ Based on this information, it was determined that the existing arrangement reflects the original order, as it would have been at the $C D N$. After the negatives were taken, processed and used in the layout of the issue, they were then filed away chronologically.

Once a better physical understanding of the collection was established, it was possible to determine the ideal intellectual arrangement that would best suit the original context of the images as well as permit easy access for staff and researchers. The Canadian Archival Standard Rules for Archival Description $(R A D)$ was used throughout the intellectual arrangement and description process in order to ensure that the organization and finding aid were consistent with museum standards.

The intellectual arrangement that was created was based on the existing physical organization, contextual research of the $C D N$ and corresponding issues

\footnotetext{
${ }^{44}$ Diana Martin (Photographer, CDN), email message to author, May 15, 2015.
} 
of the newspaper. The existing order was respected in the intellectual arrangement to preserve any original context and relationships that could be discovered by staff or researchers in the future. This decision follows the principle of respect des fonds, which states "the archivist must respect and reflect the origins of the assembled materials as an integral and organic corpus of documentation." ${ }^{45}$

The structure of the collection follows the principles of RAD for determining the hierarchy of materials within a collection. Since the CDN records were created or compiled by a single entity, it is considered a collection. ${ }^{46}$ The next level of description are series - groups of records that were created for the same activity or function. ${ }^{47}$ In this case, Series 1 consists of the negatives that were taken by $C D N$ staff photographers for use in the issues of the newspaper, and Series 2 consists of the ledger books that were used to record daily activities for eight years. The next level consists of files, which merge documents that are related by the same subject or transaction..$^{48}$ In Series 1, the file level consists of each day that photographs were taken, so one file may consist of several sleeves of negatives. This will ensure that photographs

\footnotetext{
45 Michael J. Fox and Peter L. Wilkerson, Introduction to Archival Organization and Description, (1998), 6.

46 Canadian Archival Standard Rules for Archival Description, (2008), 1-18.

${ }^{47}$ David W. Carmichael, Organizing Archival Records, (2012), 9.

${ }^{48}$ Ibid.
} 
that were taken at the same time, the same event, or by the same photographer will remain together. It also allows for one file to be easily compared to the corresponding issue of the newspaper that the negatives were printed in. Due to the large size of the collection, the negatives may never be catalogued or described at the item level, but the arrangement has been determined to allow for item level numbering and description in the future. In Series 2, each ledger book is a file, as each book contains notes from one entire year.

Physically the collection is stored in chronological order in 212 archival Hollinger boxes. Each box is labelled with the date range and contains an average of 76 glassine sleeves, with each containing an average of 10 negatives. Each sleeve is labelled with the specific day and year that the images were taken, and there is an average of 2 sleeves per day. During the inventory and arrangement process, notes were made about the content, condition of images, and any other relevant information that would be useful in the description process. 

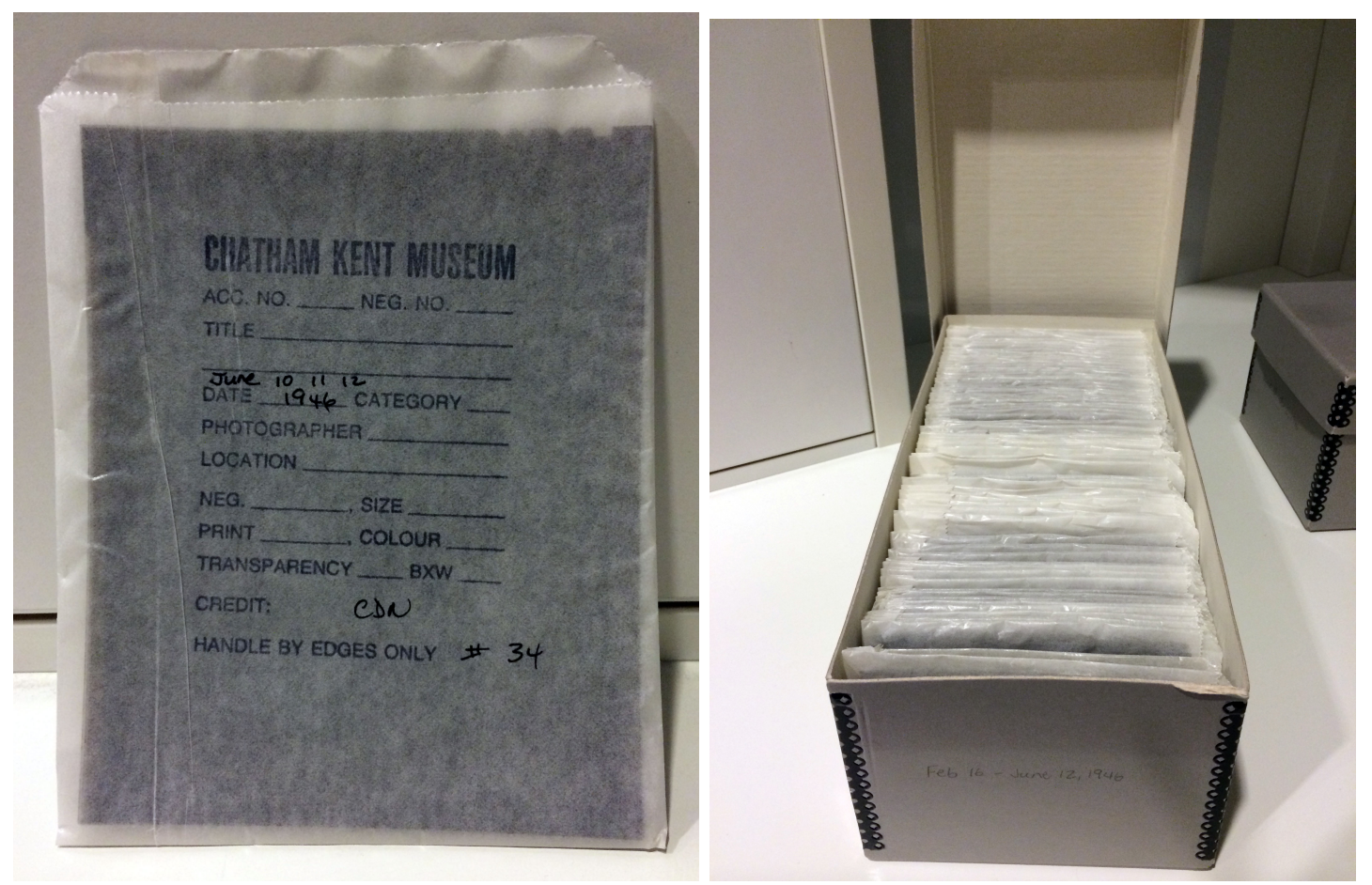

Figures 3 and 4: Current storage of the negatives at the Chatham-Kent Museum. Figure 3 (left) shows the glassine sleeves that contain negatives from one or a series of days. Figure 4 (right) shows the Hollinger boxes that the sleeves are stored in. Both the sleeves and boxes are labelled with the appropriate date range for the negatives they contain. Digital photographs taken by author, December 2014.

After the intellectual arrangement was determined, the collection was then described in the finding aid. The finding aid is an archival tool that provides descriptive information, context for the collection and allows the museum staff to have better intellectual and physical control over the collection. DACS was used to identify which elements to include in the finding aid and how to format the descriptions. The historical research discussed earlier was the basis for a biographical sketch that gives context to the collection by identifying the compiler. The document outlines each series and lists exactly what materials it contains. It also provides information for researchers such as copyright restrictions, provenance, condition and related materials. This document will 
ensure that the museum staff have a better understanding of the collection and its value to the museum, and will make future projects such as cataloguing and digitizing easier to undertake. It will also permit researchers to gain a better understanding of the contents, identify access points and potentially make new connections and discoveries. The Museum will be provided with a word processing file that will allow the staff to update the finding aid as more work is done and new discoveries are made. This will also allow for the museum to create a PDF file that can be easily added to their website, entered into their database system and shared with researchers.

\section{c. Representative Sample: Overview}

A representative sample of the collection was reviewed to allow for the description of the content and to determine the use of the negatives. The number of photographs that fell under each subject heading and the total number of negatives that were taken was determined for each day of the sample. The timing of events and holidays as well as press printing schedules was accounted for when selecting a consistent day to use. To avoid days that would be heavily skewed to one event or topic, the second Wednesday of June of each year was selected - the middle of every week, month, and year. In total, 
the sample includes 1,942 negatives and the 42 corresponding newspaper issues for one day of each year in the collection.

Using the same sample days, the negatives in the collection were then compared to the corresponding issues of the newspaper to determine how the images were used. Data gathered included the average number of images that appeared in each issue, how many negatives were taken, compared to how many were printed in the paper each day, and how many photographs taken by staff photographers versus the amount that were sourced from press agencies such as the Canadian Press, the Associated Press, and Reuters. This sample not only helped to describe the content of the images in the collection, but how they were produced and used by the CDN in this 42-year period.

\section{d. Representative Sample: Findings}

This sample of 1,942 negatives and 42 corresponding issues of the newspapers demonstrates that on average, 45 photographs were taken each day and were stored in an average of 2 sleeves. The average length of the newspaper was 29 pages, with an average of 23 photographs printed in each issue. ${ }^{49}$ Out of the average 23 photographs that were printed in each issue, $67 \%$ were produced by $C D N$ staff photographers, and the resulting $33 \%$ were

\footnotetext{
49 This does not account for photographs that appeared in advertisements.
} 
attributed to press agencies such as the Canadian Press, the Associated Press, and Reuters (fig. 5). There was a slight increase in the number of photographs taken per day throughout the entire 42-year period, but for the most part there is no noticeable pattern and there are extreme rises and falls in the numbers from year to year (fig. 6).

The negatives were classified using series of subject headings that were created based on the various sections of the newspaper from 1946-1987, and from my own experience of the content of the collection during the inventory. For example, when examining the negatives in the collection, there was a noticeable amount of photographs of vehicle accidents and disasters such as fires, storm and floods. If these specific occurrences were classified under one of the newspapers more general headings such as Local News, the content descriptions would have been very vague. The results of the sample with the total percentage of images by subject heading is demonstrated in figure 7 . In terms of content, the most common subjects in the sample negatives were Portraits (28\%), Women \& Family Life (11\%), Education \& Children (10\%), Industry and Business (8\%) and Agriculture (7\%) and Athletics (7\%). The predominance of these six subjects reflects the rural, community-based atmosphere of Chatham-Kent and the important values reflected by its society such as an emphasis on people and their relationships to one another, and a 


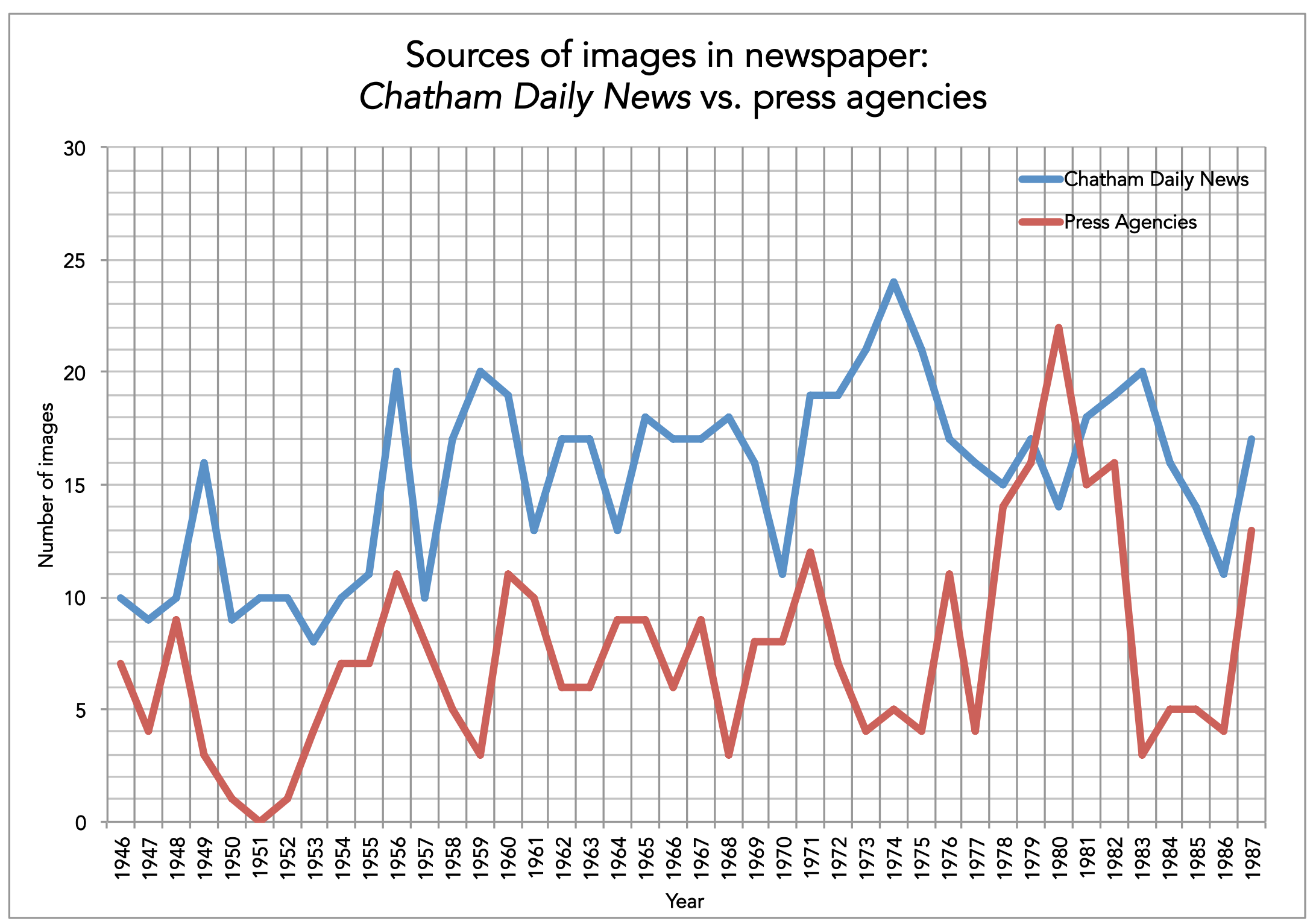

Figure 5: Chart compares the number of images from each year that were taken by CDN staff photographers to the number that were sourced from press agencies like C.P., A.P, and Reuters. Data based on representative sample. 


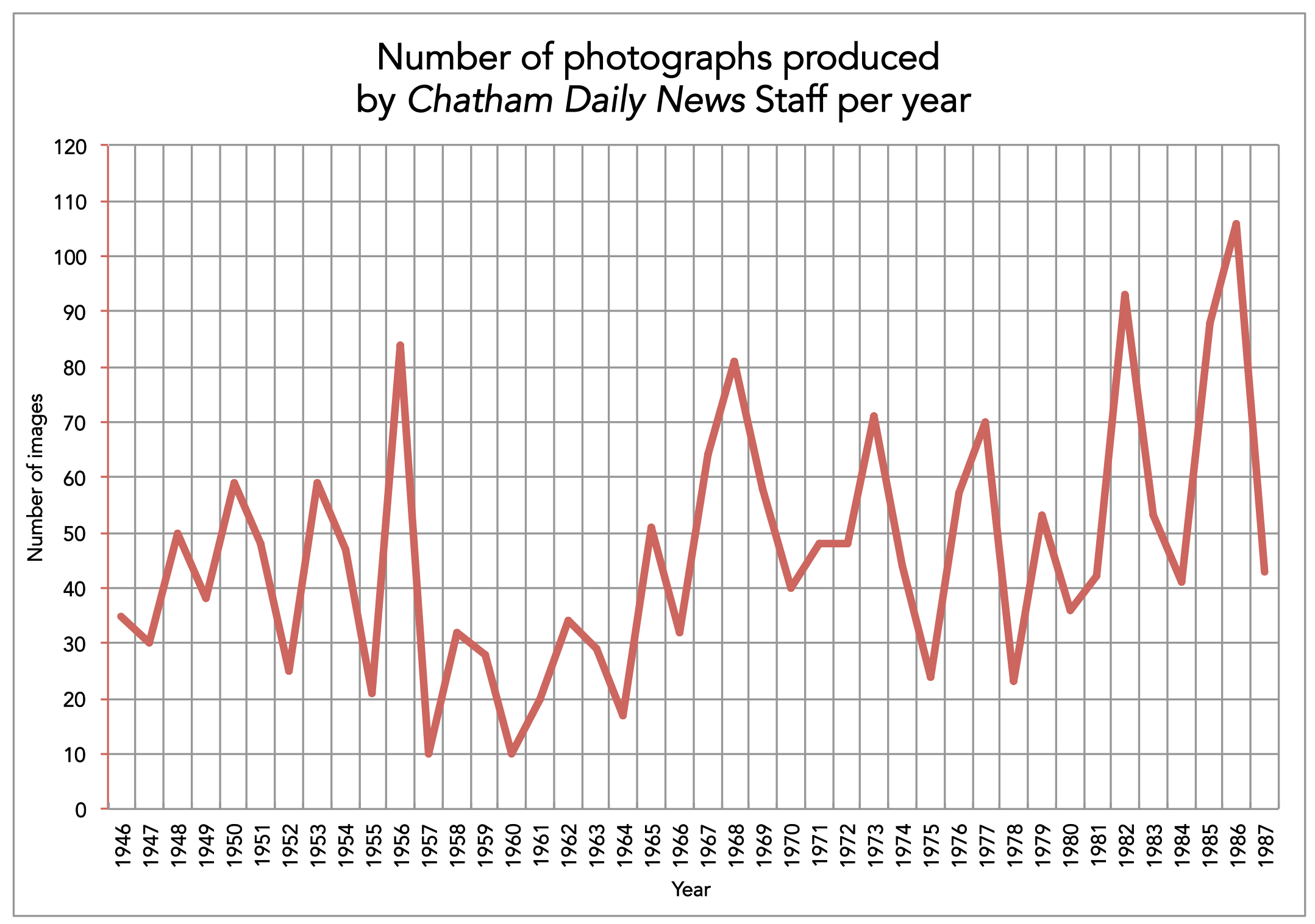

Figure 6: Graph shows the number of photographs that were produced by Chatham Daily News Staff each year from 1946-1987. There is no noticeable pattern and there are extreme rises and falls in the numbers from year to year. Data based on representative sample. 


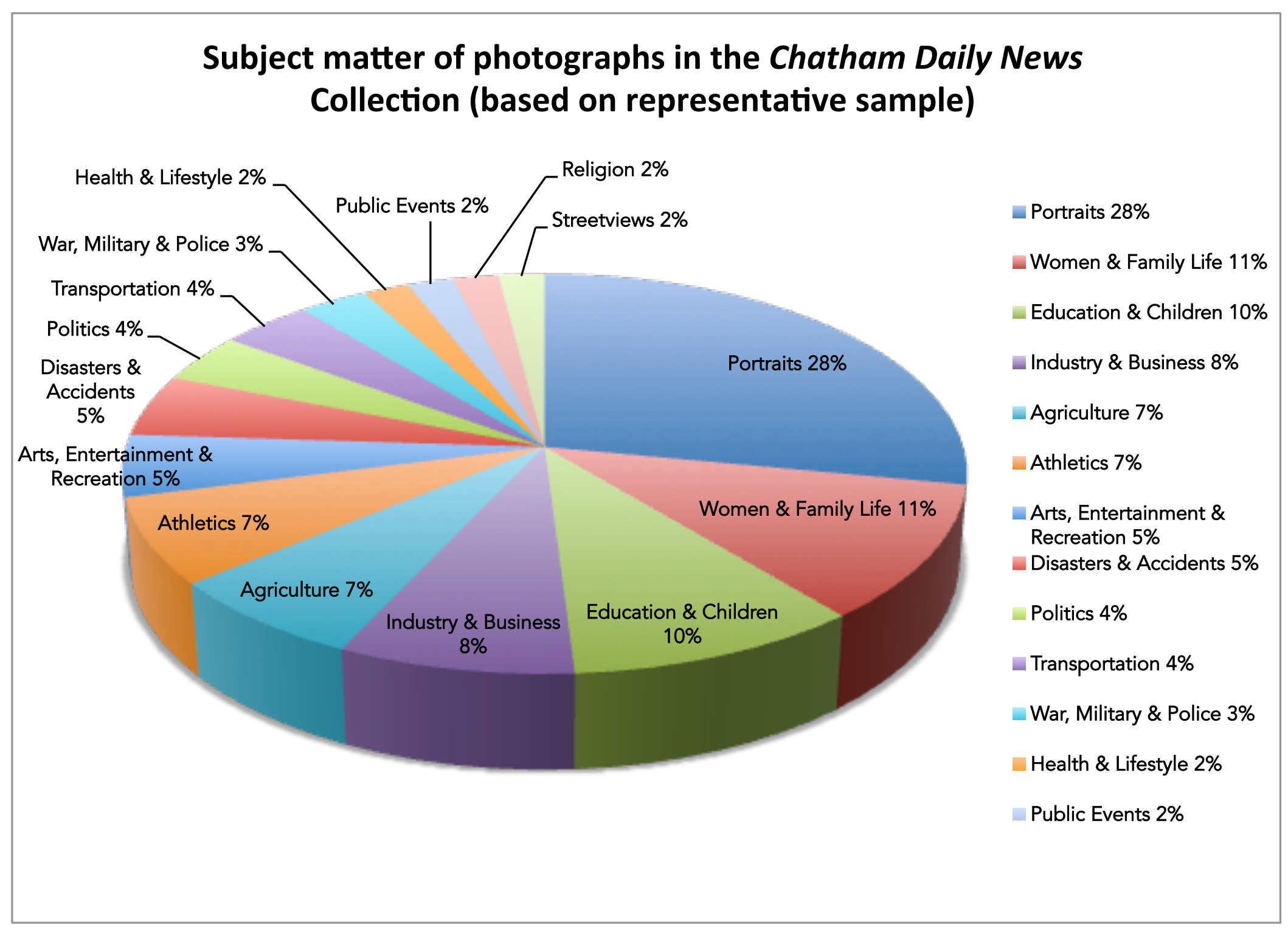

Figure 7: Chart shows the division of subject matter in negatives in the collection. Subject headings were based on newspaper headings. Data based on representative sample. 
strong connection to natural resources through agriculture and recreation. This data also demonstrates that the type of news that the CDN staff were responsible for covering was not the fast-paced, quickly evolving events of the day but the more static, low-key portraits and scenes of Chatham-Kent. This sample demonstrated that the primary focus of the CDN staff photographers was the people of the area and their activities and livelihoods. Furthermore, the low numbers of photographs in the collection with subjects such as Disasters \& Accidents (5\%), Politics (4\%), and War, Military \& Police (3\%) indicates that these types of events were mainly depicted by press agencies, not by CDN staff photographers.

Although the majority of photographs printed in the newspaper were produced by CDN staff, only 1 out of 3 negatives that they took were actually selected for publication. In order to determine why only one-third of the negatives were used, negatives in the collection from a specific event were compared to the corresponding issue of the newspaper. This comparison shows that the remaining two-thirds of the unprinted negatives are variants of the same person, scene or event. For example, there are four negatives (fig. 8) in the collection that correspond with the one photograph that appears in the June 


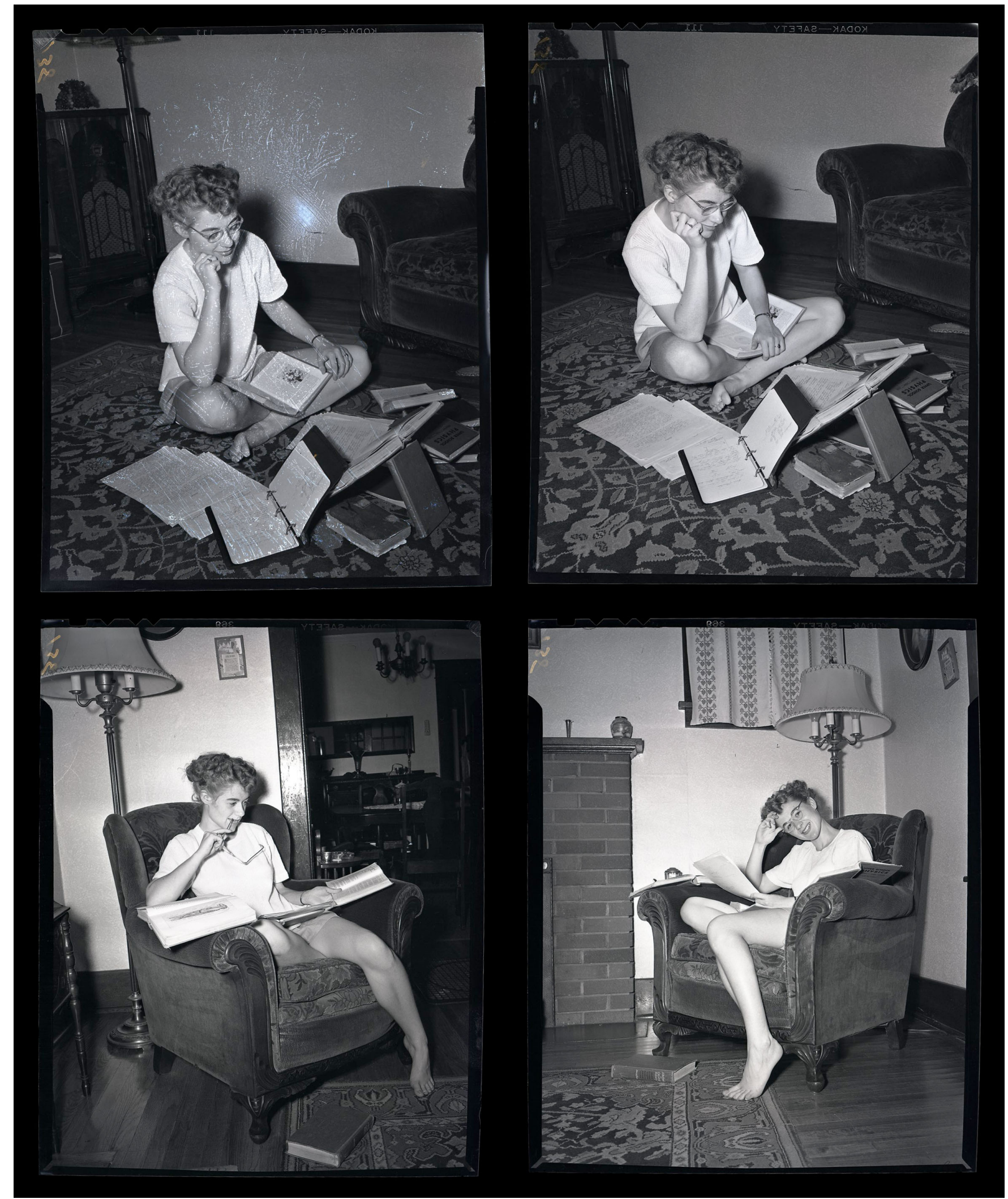

Figure 8: Photographer Unknown. Four photographs shot to depict students cramming for exams during a heat wave, July $11^{\text {th }}, 1947$. Cellulose acetate negatives, 5" x 4", Chatham Daily News Collection, Chatham-Kent Museum. 
$11^{\text {th }}, 1947$ issue, titled "Heat Fails to Stop 'Cramming.'"50 The photographer took four shots with two scene variations, the pose of the sitter changing slightly throughout each one. The upper left negative was the final negative chosen for publication (fig. 9) and depicts the student in shorts and a T-shirt, seated

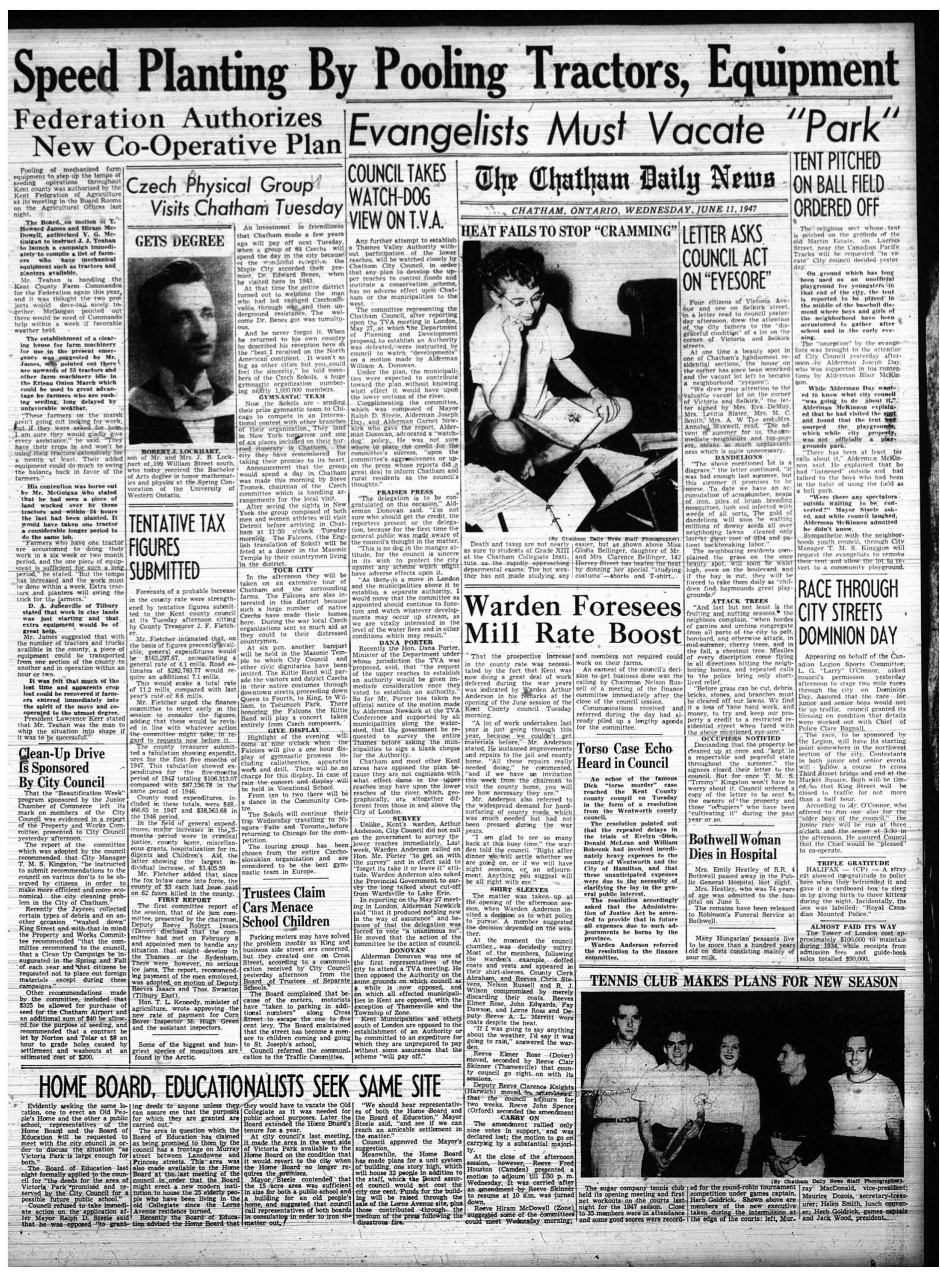

Figure 9: Page 11 from the Issue of the $C D N$ that the selected 'cramming' photograph was printed in, June $11^{\text {th }}, 1947$. Newsprint, $60 \mathrm{~cm} \times 37.5 \mathrm{~cm}$. on the floor with her books

propped in front of her. This

negative is cropped more

closely than the others to

focus on the subject, her

clothing, and her books in

order to show high school

students studying for exams

in the June heat. The

negative in the top right is

similar to the final image, but

the face of the subject is

turned away and is not as

easily identifiable. In the two bottom negatives, it is even more difficult to recognize the face of the sitter, and it is not evident what she is doing. The

50 Chatham Daily News, June 11, 1947, 11. 
unselected photographs are technically sound, but do not communicate the subject as clearly and quickly as the final negative that was chosen. This demonstrates that upon being sent to cover story, the CDN staff photographers may have been trained or instructed to take several shots to ensure that at least one would be suitable for print and would communicate the news topic to readers immediately.

The examination of issues of the newspaper from 1946 to 1987, show that, up until 1973, the CDN did not list individual credits for photographs, but would differentiate between Staff or AP Wirephoto. This is also reflected in the collection at the museum, where there is no photographer listed on the sleeves of negatives. This absence of attribution for photographs could indicate that the CDN editors wanted the paper to appear as a unified entity whose sole purpose was to provide the news in an unbiased manner. However, this could also imply that up until 1973, the staff photographers at the CDN were not professionally trained and therefore may not have been seen as worthy of recognition. As demonstrated by the earlier example, the photographer was sent out to capture a photograph with a specific subject in mind. The large format camera used, the sharp detail, and the tight framing indicates that this was not a spontaneous moment captured by the photographer that then inspired a headline. In this case, the photographer was a technical operator with specific instructions to 
illustrate a preconceived topic, not a journalist sent out to find an interesting story. For example, a written note in the collection's ledger book from 1979 reads "John McGregor Sec. School - pix in school's technical office of (3?) winners." In this instance, the editor has determined the precise location and

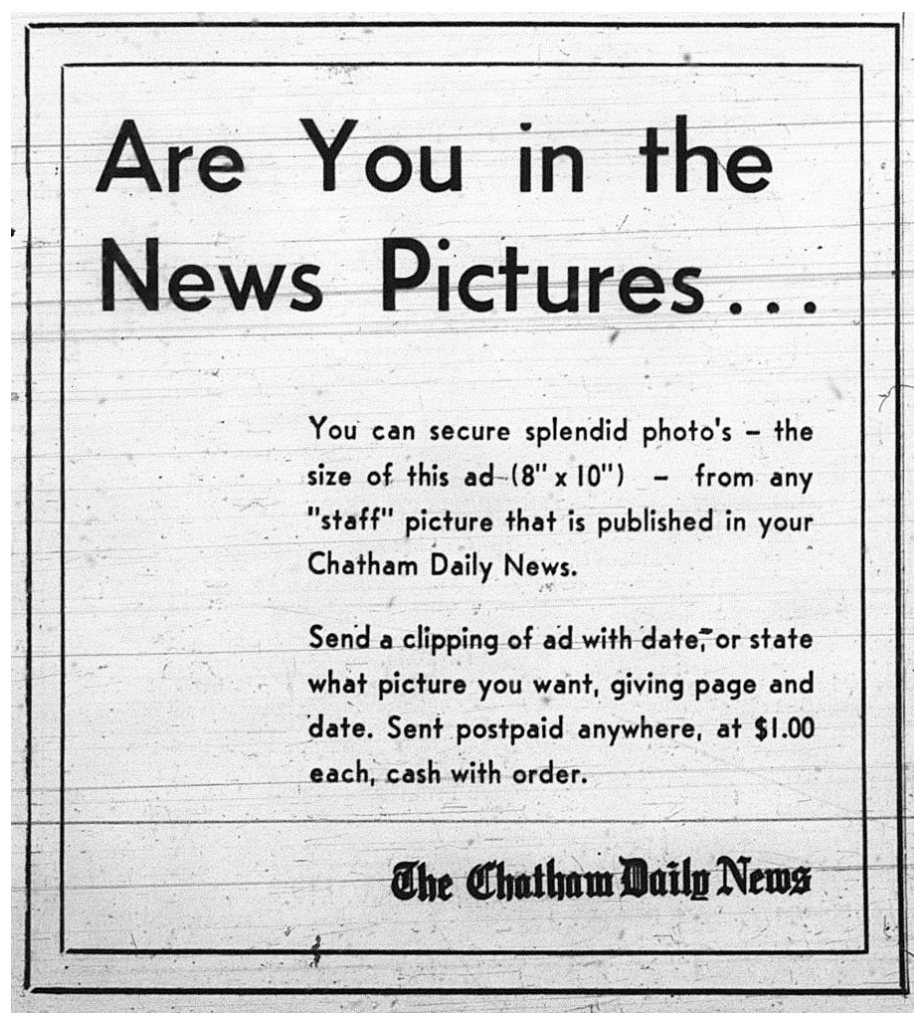

Figure 10: An advertisement from the CDN informing readers on how to obtain a copy of a photograph that appeared in the paper, 1958.

Newsprint, $7 \mathrm{~cm} \times 9 \mathrm{~cm}$. subject of the photograph for the staff member.

In a newspaper issue from 1958, an advertisement from the CDN itself (fig. 10) informed readers of how they

could obtain a copy of a photograph that appeared in the paper. Since only $67 \%$ of the images in the paper were locally contributed or taken

by the CDN staff, in a small community it is considered a special occasion to have ones photograph printed in the paper. It reads: "Are you in the News Pictures...You can secure splendid photo's - the size of this ad $\left(8^{\prime \prime} \times 10^{\prime \prime}\right)-$ from any "staff" picture that is published in your Chatham Daily News. Send a clipping of ad with date, or state what picture you want, giving page and date. 
Send post paid anywhere at $\$ 1.00$ each, cash with order. ${ }^{151}$ This demonstrates that there was a demand from the community for images of familiar people and places. This ability to identify well-known content also appears to be the primary use of the CDN collection at the Chatham-Kent Museum. According to museum staff, many of the researchers interested in the collection approach it wishing to obtain a copy of a photograph of themselves or their family that appeared in an issue of the paper.

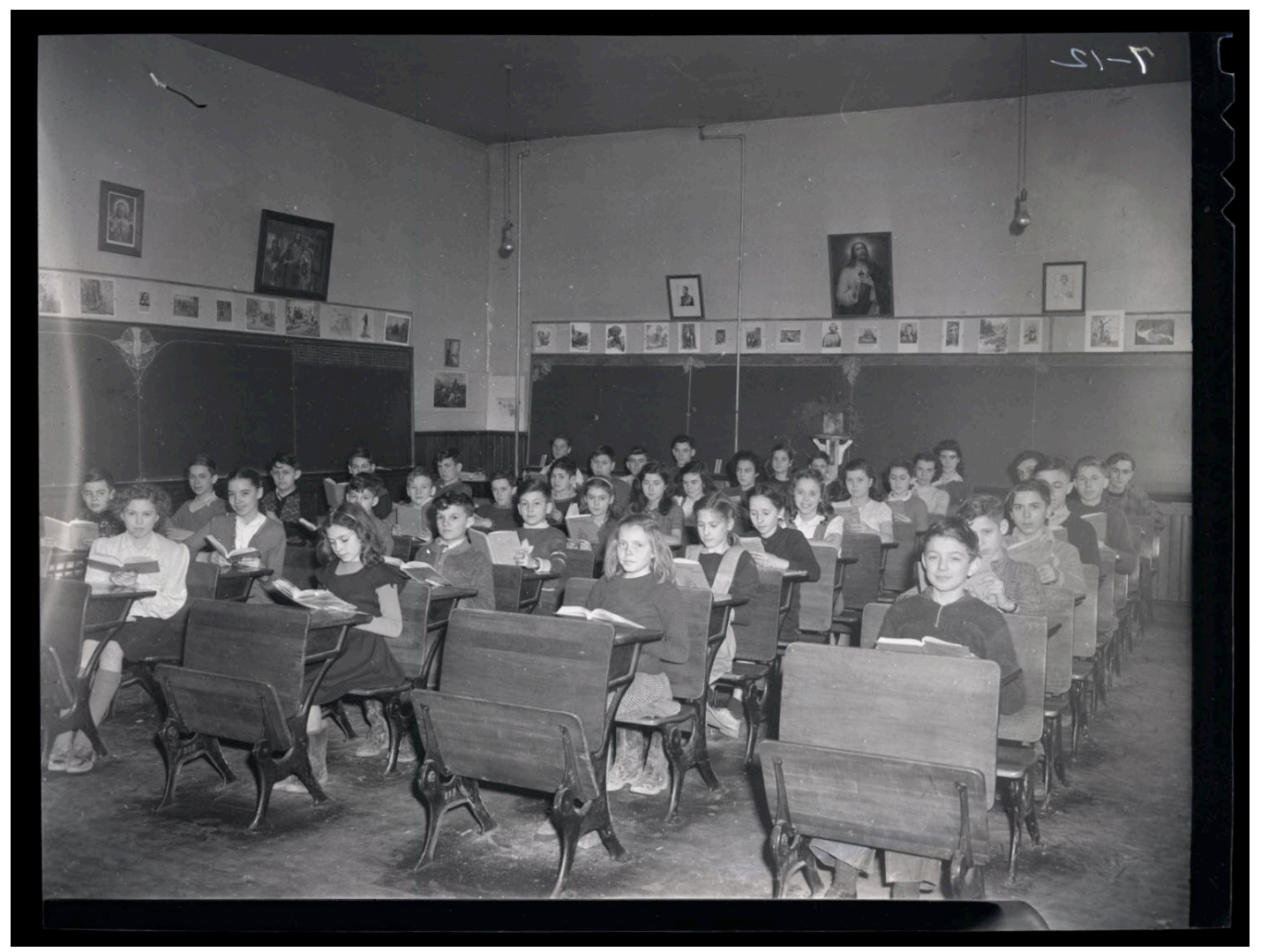

Figure 11: Photographer Unknown. A negative from the collection depicting students seated in their classroom, 1946. Cellulose acetate negative, 4" x 5", Chatham Daily News Collection, Chatham-Kent Museum.

${ }^{51}$ Chatham Daily News, June 11, 1958, 12. 
In conclusion, the data gathered from this sample indicates that the staff of the CDN focused on local events and people, and left the international news and fast-paced, high-action events to be sourced from press agencies such as the Associated Press and Reuters. This is reflected in the content of the collection, which mainly consists of photographs of every day life in the community, with a large focus on people. This sample demonstrates that the $C D N$ used photographs not only to convey information or breaking news, but to help build a community identity and allow the population of Chatham-

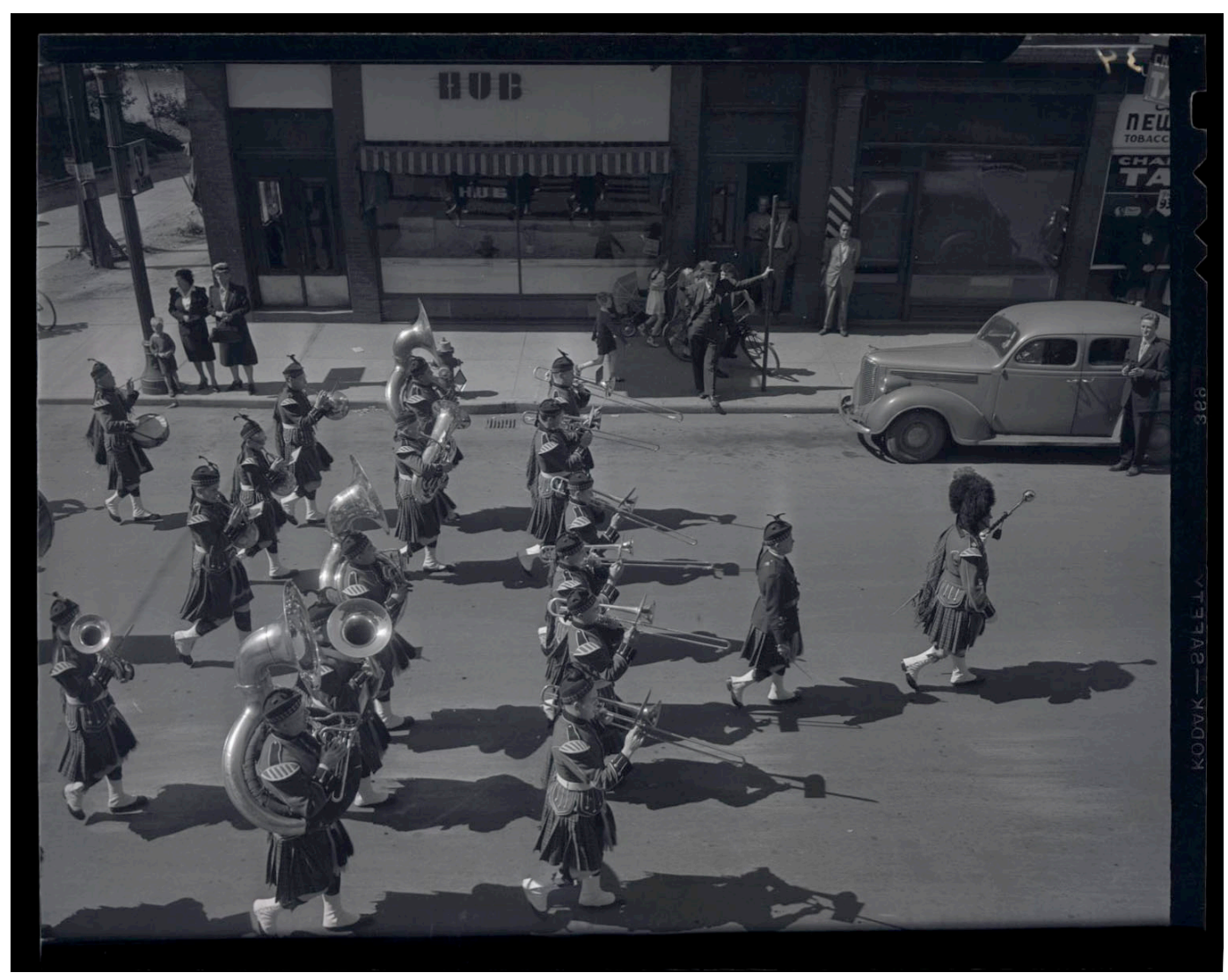

Figure 12: Photographer Unknown. A negative from the collection depicting a marching band as it parades down a local street, 1946. Cellulose acetate negative, 4" x 5", Chatham Daily News Collection, Chatham-Kent Museum. 


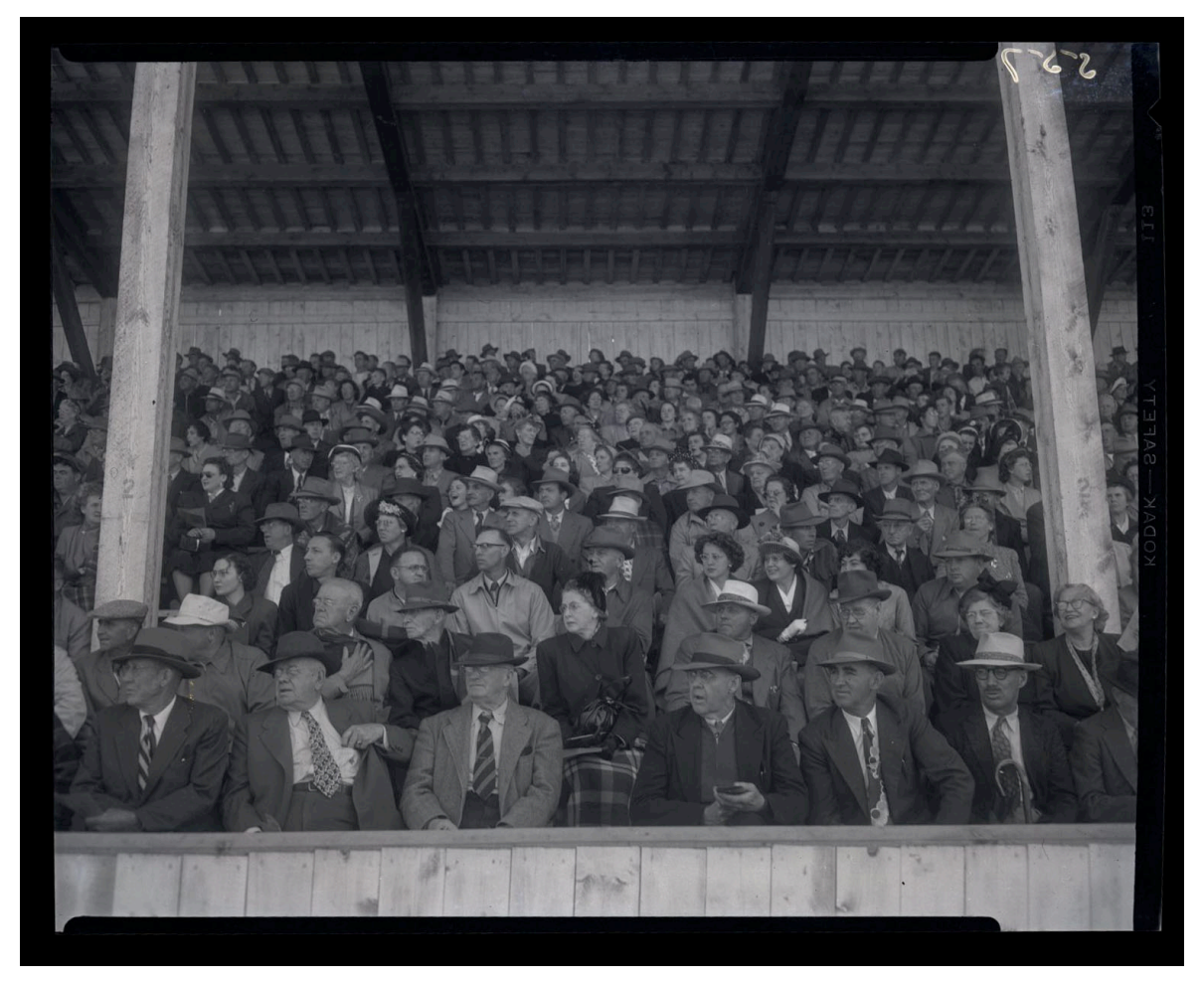

Figure 13: Photographer Unknown. A negative from the collection shows a large crowd seated in a grandstand as they watch a race, 1951. Cellulose acetate negatives, 4" x 5", Chatham Daily News Collection, Chatham-Kent Museum.

Kent to connect with the news by providing images of familiar people, places and events. This continues to be reflected in the research requests that the museum receives and solidifies the value and relevance of the collection to the museum as a document of the entire community over 42 years. This analysis shows that this collection is a significant cultural heritage asset considering the mandate of the museum is to obtain material that is important to "the development of the Municipality of Chatham-Kent and to use this material to present and promote the history of this community. ${ }^{\prime 52}$

\footnotetext{
52 "Collections," Chatham-Kent Museum, (February 21, 2014). Accessed May 10, 2015. http://www.chatham-kent.ca/Chatham-KentMuseum/Collections/Pages/Collections.aspx.
} 


\section{Conclusion}

The intellectual arrangement and description of this collection has

created access that will allow for greater research potential and for the collection to be better managed by the museum staff. It will also aid future staff and volunteers in approaching and managing this collection by making items easier to find and providing them with a historical context. Additionally, the representative sample has allowed for a broad, collection-level description that will add value to the collection and allow for connections to be made to other materials in the museum's holdings. By creating access to this collection, the museum can uphold its responsibility to preserve and share local history and the community can explore it.

However, much work remains to be done; the collection is in need of partial rehousing and preservation treatments in order to slow the rate of deterioration, ${ }^{53}$ and it should be digitized as soon as possible so that any unaffected negatives can be captured before they begin to deteriorate. The intellectual arrangement created during this thesis project currently allows for items to be located by date, however it cannot currently be searched by subject. The museum staff noted that some researchers approach the collection looking for a specific photograph, but attempt to search by subject, not by date. For

\footnotetext{
53 Refer to the finding aid for more detail regarding the condition of the collection
} 
example, a researcher may be looking for a photograph of a hockey team that they estimate could have been taken anywhere from 1960 to 1965 . This vague date range leaves approximately 28,000 possible negatives. Searching through such a large amount of negatives would not only be time consuming for the researcher and staff, but would also cause unnecessary handling of the negatives.

In order to solve this problem of access by subject, the collection should be scanned and entered into a database, so that key terms and descriptions can be added. The collection would be searchable by the intellectual order (which is chronological and matches the original order) but could also be searched by subject heading. It is important, however, that the subject headings used are standardized in order to increase interoperability within the museum itself and outside organizations. For example, the earlier example of a photograph of a hockey team could be described using the following terms from the Library of Congress Subject Headings: 1. Athletics. 2. Hockey. 3. Ice hockey 4. Hockey teams. Standardizing the vocabulary used for subject headings would help to increase access to the collection by creating intellectual links to existing people, places, times, and themes. ${ }^{54}$

\footnotetext{
${ }^{54}$ Elisa Lanzi, and Howard Besser. Introduction to Vocabularies: Enhancing Access to Cultural Heritage Information, (1998), 4
} 
For many years the community has been unaware of this collection or unable to use it. It is my hope that this thesis will aid future researchers and museum staff in accessing the collection to add to the information I have gathered and allow for future discoveries. This thesis has revealed that the Chatham Daily News acted as an operator for building a community atmosphere by acting as a link between the individual and their community. Just as the CDN has played a key role in capturing the identity of the area, it is now the museum's role to shape and maintain the history and character of the community of Chatham-Kent through these photographs. In the same way that these photographs forged relationships when they were published in the newspaper, they will create new connections as a new generation of the community interacts with them and solidify the collection's significance as an irreplaceable collective heirloom. 


\section{Inventory \& Finding Aid for \\ The Chatham Daily News Collection}

Chatham-Kent Museum

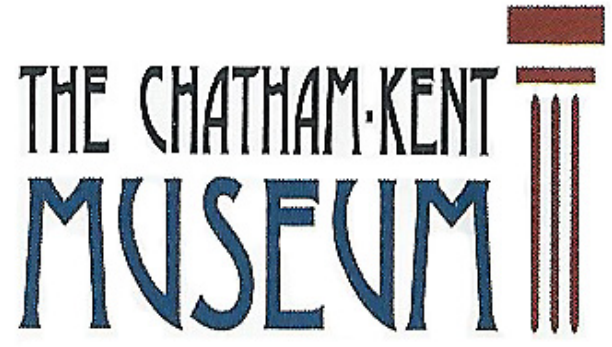




\section{THE CHATHAM DAILY NEWS COLLECTION}

\section{COLLECTION DESCRIPTION}

Title: Chatham Daily News Collection [graphic materials and textual records]

Dates: 16 Feb. 1946-30 Nov. 1987

Extent: ca. 300,000 photographs : acetate negatives, b\&w

ca. 10,000 photographs: gelatin silver, b\&w

8 bound volumes : $35 \times 2 \times 3 \mathrm{~cm}, 400$ pages

\section{Administrative History:}

The Chatham Daily News is a daily newspaper that serves the city of Chatham and surrounding areas. Located in South-western Ontario, ChathamKent is primarily an agricultural and industrial area home to approximately 103,000 residents. ${ }^{55}$ It was the site of the historic Battle of the Thames during the war of 1812 and is also home to the Dawn Settlement, a community established by Josiah Henson, a major figure in the Underground Railroad and the inspiration for the main character of Harriet Beecher Stowe's novel, Uncle Tom's Cabin. ${ }^{56}$ Chatham is also home to one of the earliest automobile manufacturers in Canada, Gray-Dort Motors Ltd., and the world's largest vintage automobile auction and restoration house, RM Classic Cars. Among notable citizens are author Robertson Davies; championship figure skater Shae-Lynn Bourne; T.J. Brodie, NHL hockey player with Calgary flames; and Ferguson (Fergie) Jenkins, MLB baseball player for the Philadelphia Phillies, Chicago Cubs, Texas Rangers, and Boston Red Sox.

The areas first newspaper was the Chatham Journal, which was in print from 1841 to 1844 . The Chatham Planet (predecessor to the CDN) was published weekly from 1857 to 1891, after which it became the Chatham Daily Planet until December 29, 1922. ${ }^{57}$ In 1922 the Chatham Daily Planet and Banner News

\footnotetext{
55 Statistics Canada. 2012. Chatham-Kent, Ontario (Code 3536020) and Chatham-Kent, Ontario (Code 3536) (table). Census Profile. 2011 Census. Statistics Canada Catalogue no. 98-316-XWE.

${ }^{56}$ Beecher Stowe, Harriet. Uncle Tom's Cabin Or, Life Among the Lowly (Cleveland, Ohio: John P. Jewett \& Company, 1852).

57 Jim, Gilbert, and Gilbert Lisa. "Times May Change, but Some Issues Do Not." Chatham Daily News, July 13, 2012, Life sec. Accessed March 19, 2015.

http://www.chathamdailynews.ca/2012/07/13/times-may-change-but-some-issues-do-not.
} 


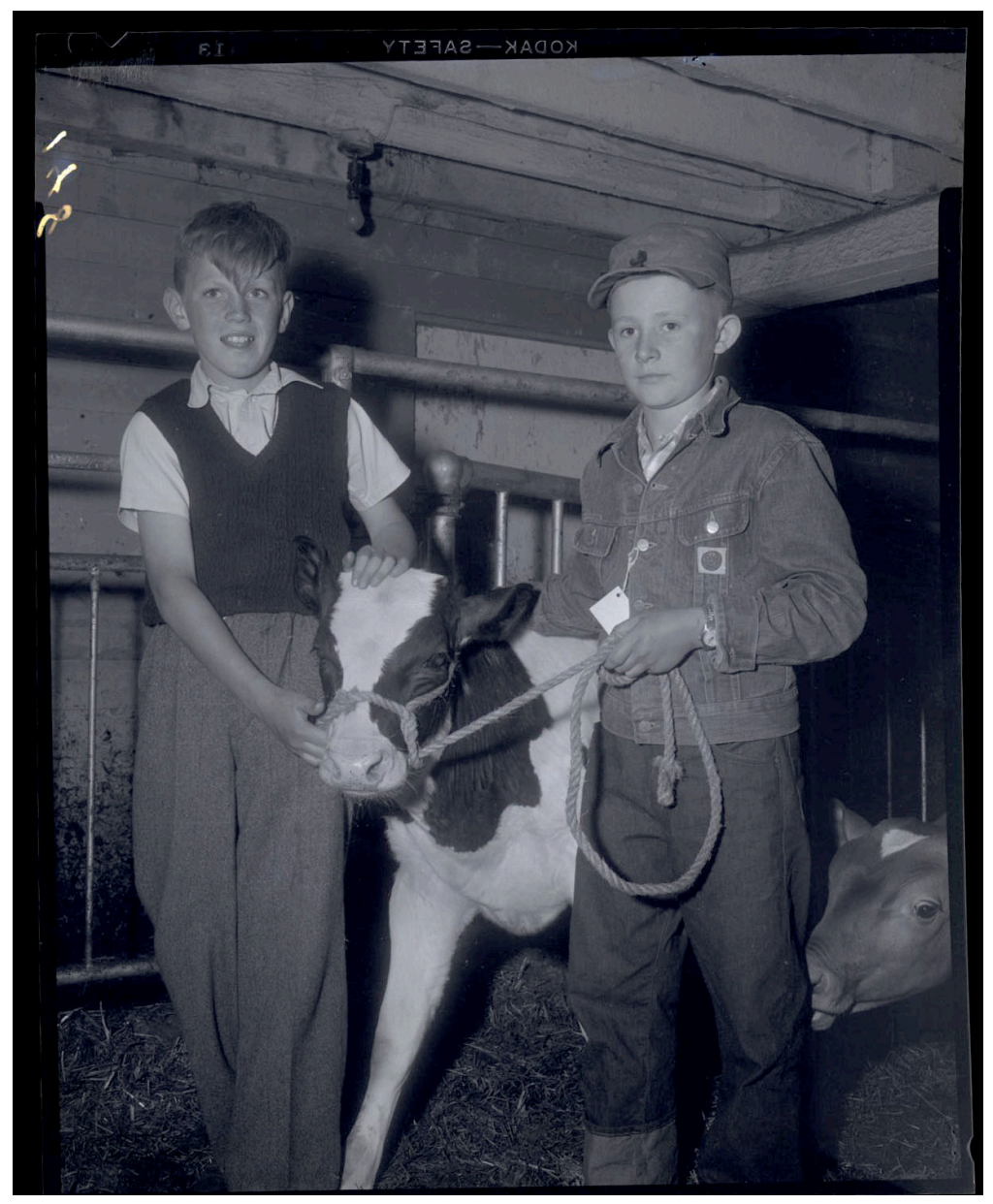

Figure 14: Photographer Unknown. Two boys show off their calf in a barn, 1954. Cellulose acetate negative, 5" $\times 4$ ", Chatham Daily News Collection, Chatham-Kent Museum.

Figure 15: Photographer Unknown. A newly married couple cuts the cake at their wedding, 1946.

Cellulose acetate negative, $4 " \times 5 "$, Chatham Daily News Collection, ChathamKent Museum.

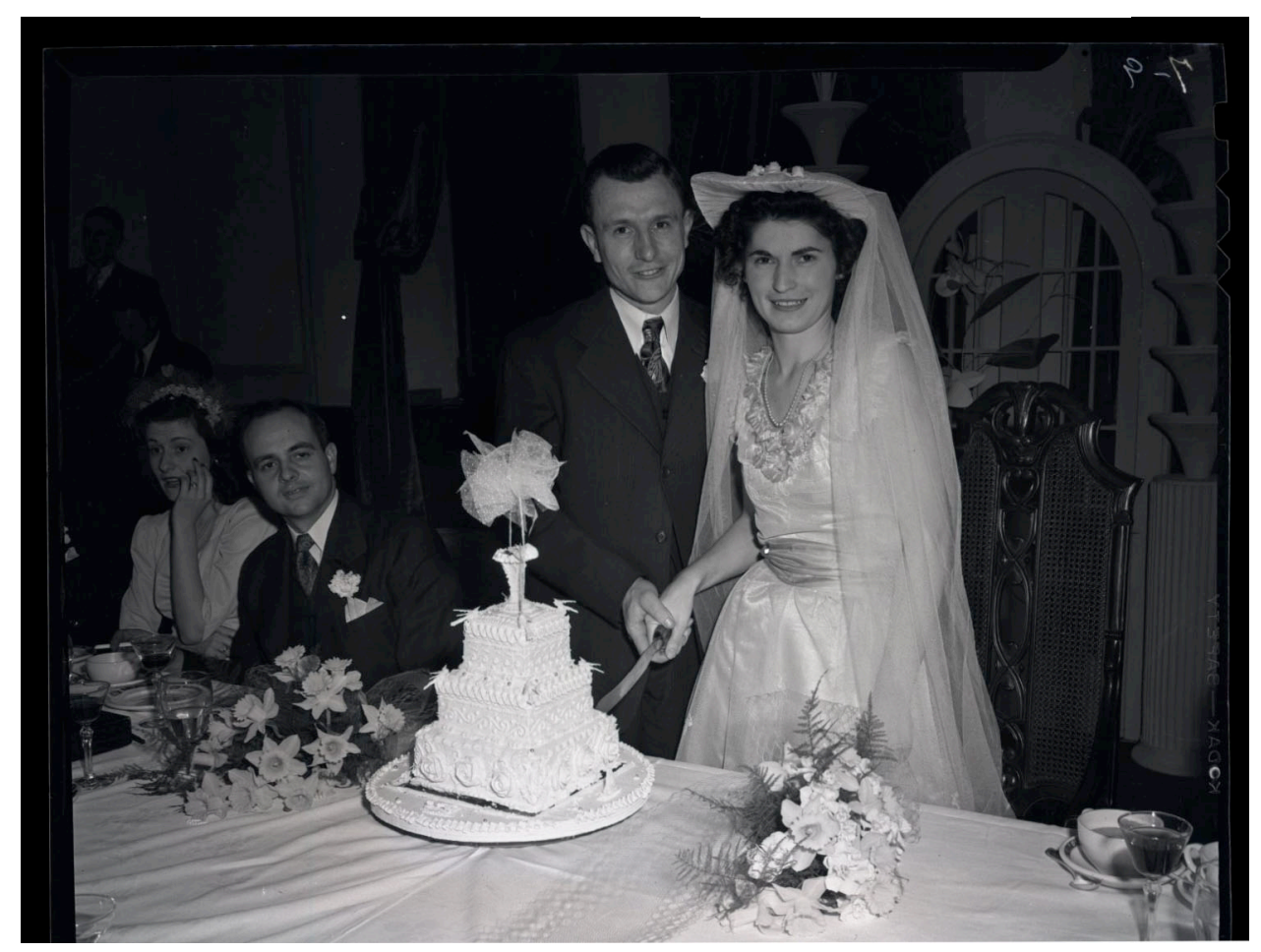


merged to create the Chatham Daily News. The CDN's headquarters was originally located at 45 Fourth Street and is presently located at 138 King Street West.

In 1946 the CDN claimed to be "First with the News" and "The Home Paper for South-western Ontario." ${ }^{58}$ It featured sections such as World Affairs, Weather, the Voice of the People, Sports Spots, Farmers Markets and Classifieds, With the Women and tidbits like the Daily Recipe and Flashbacks: From the Files of the News. A 1946 issue notes the Chatham Daily News' association with the Canadian Press: "The news, with which is amalgamated the Daily Planet, is published each afternoon (Sundays and legal holidays excepted) by the Chatham Daily News Limited. Member of the Canadian press and the Andis Bureau of Circulation. The Canadian press is exclusively entitled to the use for republication of all news dispatched in this newspaper credited to it or to the Associated Press or Reuters and also the Local News published therein. " 59 By 1948 the Chatham Daily News claimed to be printing 300,000 issues per month (or apx. 11,538 issues per day). ${ }^{60}$ In 1953, an issue sold for 5 cents and by 1958 it claimed to be "The only paper devoted exclusively to developing Kent" and was the source for "News for busy readers." ${ }^{61}$

Today the CDN is currently owned by Canoe Sun Media Community Newspapers, who are the Publishers of eight newspapers across Chatham-Kent: The Chatham Daily News, The Citizen, Home Hunting Guide, Smart Shopper, Chatham This Week, Today's Farmer, Wallaceburg Courier Press and the Leader Spirit. Sun Media also delivers 45 million flyers each year, locally and nationally. The CDN's distribution consists of 300+ carriers and drivers, printing an average of 6,280 copies daily. ${ }^{62}$ In 1969 a one-year daily subscription in Kent County cost $\$ 17$ for same day delivery, ${ }^{63}$ which would equal approximately $\$ 109$ today. However, the subscription has doubled in cost since 1969; a one-year daily

\footnotetext{
58 Chatham Daily News, June 13, 1946, 1.

59 Ibid., 4.

60 Chatham Daily News, June 9, 1948, 17.

${ }^{61}$ Ibid., June 13, 1958, 1.

62 Newspapers Canada, "2013 Daily Newspaper Circulation Report," (May 1, 2014). Accessed March 17, 2015. http://www.newspaperscanada.ca/sites/default/files/2013 Daily Newspapers Circulation Report FINAL.pdf, Page 1.

${ }^{63}$ Chatham Daily News, June 11, 1969, 1.
} 
subscription to the CDN now (2015) costs $\$ 232.92$. Comparably, the London Free Press prints an average of 78,163 copies daily and a one-year subscription with delivery costs $\$ 274.58,{ }^{64}$ and the Toronto Star prints an average of 360,515 copies daily with a yearly subscription and delivery cost of $\$ 649.80 .{ }^{65}$ These numbers show that compared to the circulation of well-known newspapers in Southwestern Ontario, the CDN has a relatively small circulation and is economically priced. In terms of cost, the CDN has always been affordable for the average family. In 1969 a one-year subscription would have only cost approximately 19 cents per issue. Today, a subscription is still very affordable at $\$ 1.50$ per issue with a one-year subscription. These subscription prices further demonstrate that the role of the CDN was to provide the news and make it easily accessible to the community.
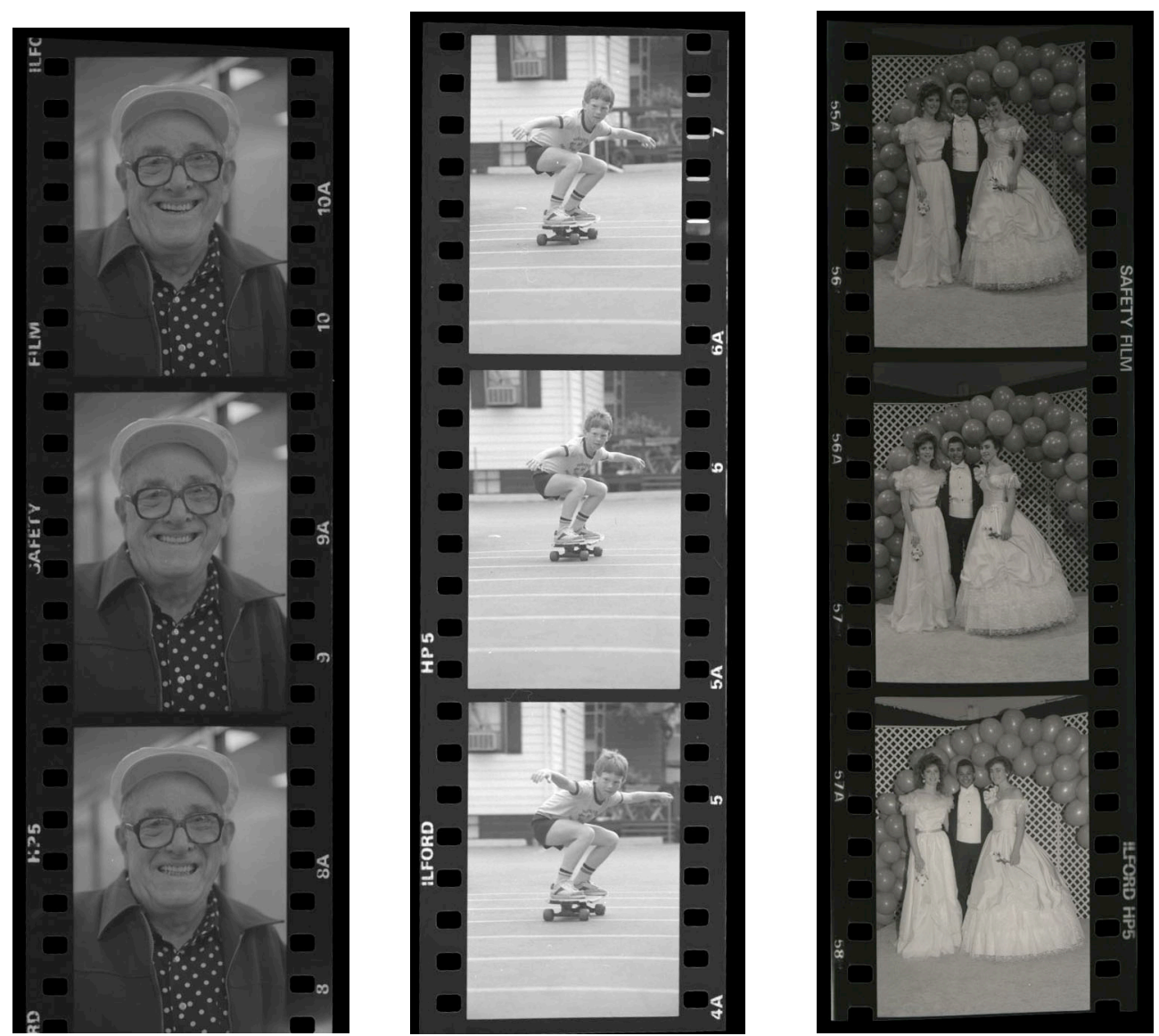

Figures 16-18: Photographers Unknown. Three strips of 35mm negatives taken by CDN staff in 1987. Illustration 16 (left) shows a closely-cropped portrait of an elderly man. Figure 17 (centre) depicts a young boy riding his skateboard, and figure 18 (right) a group of teens at a formal dance. Cellulose acetate negatives, $54 \mathrm{~mm} \times 35 \mathrm{~mm}$, Chatham Daily News Collection, Chatham-Kent Museum.

64 Newspapers Canada, "2013 Daily Newspaper Circulation Report," 2. 65 Ibid., 2. 


\section{Chronology:}

1890 Editor of The Chatham Planet, Talbot Warren Torrance, resigns and is replaced by E.A. Hutchinson

1900 Chatham Banner-News, A.C. Woodward - Owner, Alonzo T.

Macdonald - editor

1901 Editor of The Chatham Planet, E. A. Hutchinson, resigns, and is replaced by R.W. Angus

192230 Dec. last issue of The Chatham Daily Planet

1922 The Chatham Daily Planet merges with the Banner-News, edited by T.D. Niven and W.E. Cruickshank

1947 Chatham Daily News bought by Thompson Company Ltd.

1950 J. Keith Stewart - General Manager, Joseph Emmott - Editor

1957 J. Keith Stewart - General Manager, Ray Munro - Editor

1958 J. Keith Stewart - Publisher, J.M. Bowers - General Manager

1963 J. Keith Stewart - Publisher, J.M. Bowers - General Manager, R. G. Dunlop - Managing Editor

1967 J. Keith Stewart - Publisher, J.M. Bowers - General Manager, Douglas C. Waite - Managing Editor

1969 J.M. Bowers - Publisher and General Manager, Douglas C. Waite Managing Editor

1972 William Telfer - Publisher and General Manager, Douglas C. Waite Managing Editor

1979 F.M. Dundas - Publisher and General Manager, Steve Zak - Managing Editor

1981 R.B. Renaud - Publisher and General Manager, Steve Zak - Managing Editor

1985 F. Ian Rutherford - Publisher and General Manager, Steve Zak Managing Editor

\section{Custodial History:}

The Chatham Daily News Collection was officially donated to the Chatham-Kent Museum on December $8^{\text {th }}, 1990$. Current CDN staff noted that the collection was donated to the museum because it would ensure that they would be archived and made accessible to the general public, and they did not have the space to continue to store them. ${ }^{66}$ Museum accession documents and donation agreements show that the donation included "125 boxes of negatives

${ }^{66}$ Diana Martin, e-mail message to author, May 15, 2015. 
(4x5" format predominantly), some contact prints; used for publication and consideration for publication in the Chatham Daily News."

\section{Arrangement notes:}

A note from 1994 outlines the costs invested in the CDN collection by the museum, including 180 acid-free boxes and 1800 envelopes, indicating that the negatives were moved from the original 125 boxes to the new 180 boxes shortly after arrival at the museum. The sleeves bear a stamp that notes the date of the negatives inside. Museum records do not show why or how the negatives were moved from these original boxes, however it is likely that the larger boxes used for transport from the CDN were not archival or suited to storage and retrieval at the museum.

The negatives are still arranged in chronological order and there is no record of any physical changes during this movement. According to current CDN staff, this chronological storage matches the manner in which negatives are presently stored at the $C D N$; negatives are stored in a paper sleeve with the date written on them, and the sleeves are stored in chronological order from oldest to most recent. ${ }^{67}$ Based on this information, it was determined that the existing arrangement reflects the original order, as it would have been (and still is) at the CDN. After the negatives were taken, processed and used in the layout of the issue, they were then filed away chronologically.

\section{Physical description note:}

Overall the collection is in fair condition. Most negatives show signs of wear from repeated handling, including scratches and fingerprints. This damage would have occurred when the negatives were in use at the Chatham Daily News. While the boxes that the collection is stored in are acid-free, the negatives are housed in non-archival glassine sleeves. Some negatives show an iridescent ring of colour where the emulsion of the negative was in contact with the sleeve. The negatives in the collection have a cellulose acetate film base, as indicated by the manufacturers edge printing. Although this film base is more stable than cellulose nitrate film, the collection is beginning to show signs of chemical deterioration, specifically vinegar syndrome. This type of deterioration consists of the breakdown of the plastic film base, a process that produces acetic acid. ${ }^{68}$ As noted in a leaflet produced by the Northeast Document

\footnotetext{
67 Ibid.

68 "Preservation Leaflet 5.1 A Short Guide to Film Base Photographic Materials: Identification, Care, and Duplication." Northeast Document Conservation Center. 2012. Accessed May 5 ,
} 

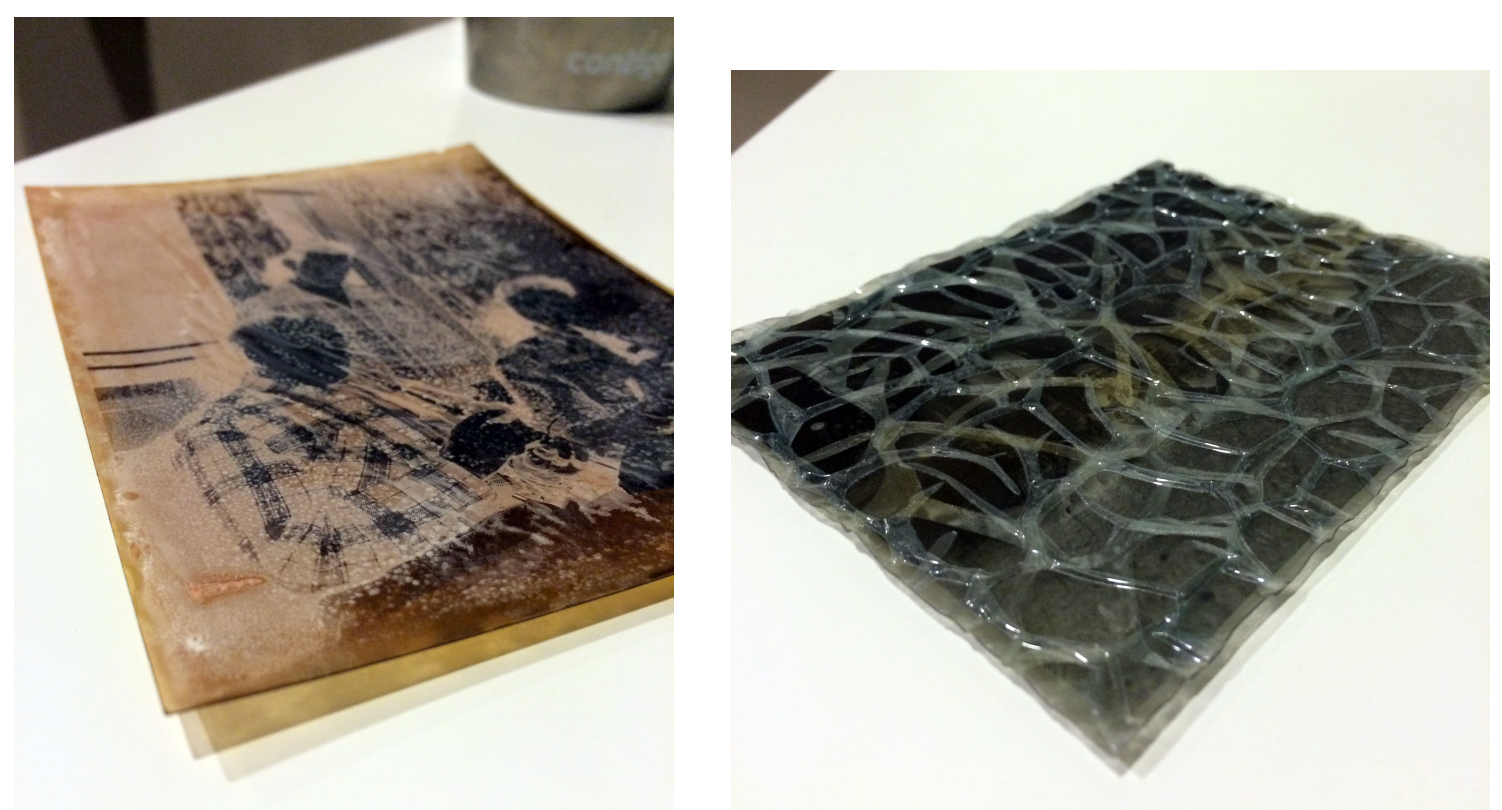

Figure 19 (left): This negative can be classified under vinegar syndrome deterioration Level 2, where negatives begin to curl at the edges, turn red or blue, and emit a strong vinegar odour. Bubbles and crystals also begin to form on the film. This negative has turned a dark amber colour and is covered in a fine white powder. Digital photograph taken by author, December 2014.

Figure 20 (right): This negative has reached the maximum level of vinegar syndrome deterioration, Level 6. Channels have formed throughout the film and the negative has turned blue. Digital photograph taken by author, December 2014.

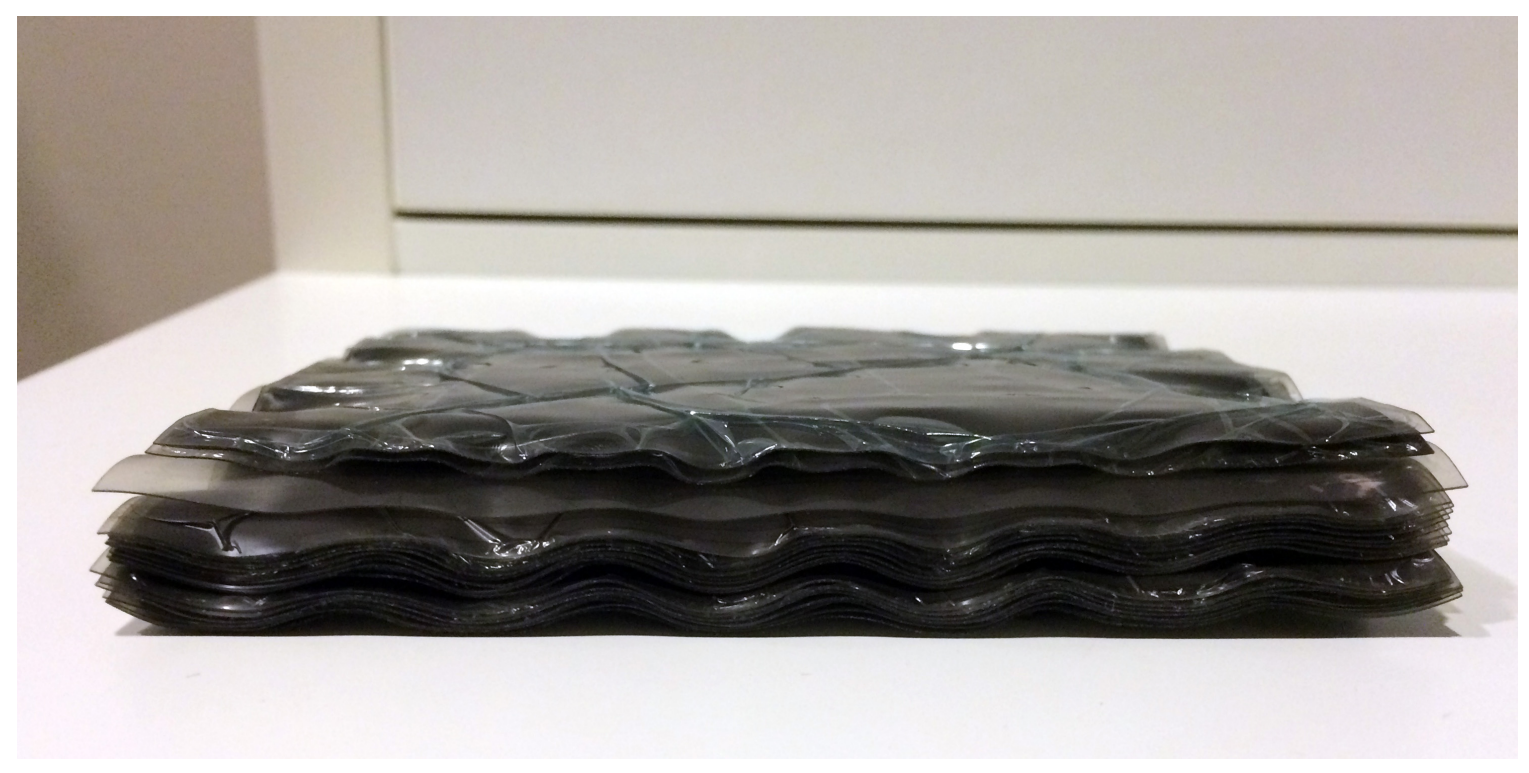

Figure 21: A side view of a stack of negatives shows the severe warping and channelling of negatives that have reached Level 6 of vinegar syndrome deterioration. Digital photograph taken by author, December 2014.

2015. https://www.nedcc.org/free-resources/preservation-leaflets/5.-photographs/5.1-a-shortguide-to-film-base-photographic-materials-identification,-care,-and-duplication. 4. 
Conservation Centre, vinegar syndrome is "autocatalytic: once deterioration has begun, the degradation products induce further deterioration. " ${ }^{69}$ Affected negatives in the collection show signs of a white, powdery deposit and emit a strong acidic vinegar-like odour. Negatives also show warping, and separation of the emulsion from the base with severe channelling. Negatives displaying the most advanced levels of vinegar syndrome are predominantly from the years 1958-1961 (refer to the container list for specific condition levels for each container). The rate of deterioration in this collection will increase over time due to the established presence of vinegar syndrome and high temperature and humidity levels in the collection storage are.

The contact prints in the collection also show signs of deterioration. The strips have begun to curl inwards and have a distinct brown staining. Since the contact prints would have been used for easier viewing and the selection of negatives for print, excessive time and care would not have been taken to make the prints. The deterioration is likely a result of poor processing or the use of low quality chemicals and papers.

The ledger books are in fair condition. The front and back covers as well as the bindings are all intact, although some of the corners are lightly worn. Several of the covers show dark spots that may be dust and grime or possibly mould. The inside pages are in good condition and are not warped, brittle or attached to one another.

Accruals: No further accruals expected.

\section{Conditions governing access:}

As outlined in the donation agreement between the Chatham Daily News and the Chatham-Kent Museum, the Chatham Daily News and its publishers retain the right of access to the negatives as required, but the museum obtains copyright to the negatives.

As of 2015 the Chatham Daily News Collection has not been digitized or put online, and is not currently listed in the museum's catalogue or database beyond a collection description. Archival and research resources at the Chatham-Kent Museum are accessible to the public by appointment only from 9:00 a.m. to 5:00 p.m. Monday to Friday. Appointments must be made at least

69 lbid. 
24 hours in advance. The museum is open 1:00-5:00 p.m., seven days a week.

To view the collection, contact:

Stephanie Saunders, Curator

Chatham-Kent Museum

75 William Street North

Chatham, ON N7M 4L4

ckcccmuseum@chatham-kent.ca

519-360-1998

Copyright: No copyright restrictions.

\section{Associated Materials:}

The Chatham-Kent Museum holds original copies of the Chatham Daily News from 1906 to 1963. Issues from 25 Oct. 1906 to 20 Feb. 1963 are located in Box N-05, Folders 1-11. Issues from 23 Feb. 1963 to 29 Mar. 1990 are located in Box N-06, Folders 12-15.

The Chatham-Kent Public Library holds copies of The Chatham Daily News and the Chatham Planet on microfilm from 1895 to 1975 . Microfilm readers are available for appointments on request. To access the online catalogue: search.ckpl.ca or contact:

Chatham-Kent Public Library 120 Queen Street, Chatham, ON N7M 2G6 CKlibrary@chatham-kent.ca 519-354-2940

\section{Scope and Content:}

The collection contains ca. 300,000 black and white acetate negatives and ca. 10,000 black and white contact prints produced by staff photographers for consideration for publication in the Chatham Daily News from 1946 to 1987. The collection also contains eight ledger books for the years 1975 and 1977-1983. These ledger books contain daily notes (presumably written by the editor) pertaining to which stories needed to be covered, what photographs needed to be taken, and which staff member would cover each event. The 
negatives depict the people, places, and daily events of the Municipality of Chatham-Kent, located in Southwestern Ontario.

The collection is currently organized chronologically and consists of 212 archival Hollinger boxes. Each box contains an average of 76 sleeves that contain an average of 10 negatives. Each sleeve is labelled with the specific day and year of publication, and most days have an average of 2 sleeves per day.

The collection is arranged into the following series, files and items:

Series 1 : Negatives

Files 1.1-1.16013 : Sleeves

Series 2 : Ledger Books

Files 2.1-2.8 : Books 


\section{THE CHATHAM DAILY NEWS COLLECTION}

\section{SERIES DESCRIPTIONS}

Series descriptions: Due to the size of the collection, time constraints, and the similarities of records, extent was completed on the series as a whole, but not at the file level.

\section{Series 1: Negatives}

Dates: 16 Feb. 1946-30 Nov. 1987

Extent: 16,013 sleeves

Note: Includes 16,013 sleeves containing ca. 300,000 b\&w acetate negatives, ca. 10,000 b\&w contact prints

\section{Scope and Content:}

Series 1 consists of ca. 16,013 sleeves containing ca. 300,000 black and white acetate negatives and ca. 10,000 black and white contact prints produced by staff photographers for consideration for publication in the Chatham Daily News from 1946 to 1987 . They are predominantly 4" $x 5^{\prime \prime}$ format, but there are also $2.5^{\prime \prime} \times 2.5^{\prime \prime}$ and $35 \mathrm{~mm}$ formats. Contact prints only exist for $35 \mathrm{~mm}$ negatives. Each box contains an average of 76 sleeves that contain an average of 10 negatives. Each sleeve is labelled with the specific day and year of publication, and on average there are 2 sleeves per day. The sleeves are stored in 212 archival Hollinger boxes.

Files 1.1-1.16013 : Sleeves 


\section{Series 2: Ledger Books}

Dates: $1975,1977-1983$

Extent: 8 bound volumes : $35 \times 2 \times 3 \mathrm{~cm}$

\section{Scope and Content:}

Series consists of ledger books containing daily notes (presumably written by the editor) pertaining to which stories needed to be covered, what photographs needed to be taken, and which staff member would cover each event. The notes do not contain any explicit direction as to how many or in what style the photographs were to be taken. Occasionally the notes mention specifically what should be depicted, for example a note from 1979 reads "John McGregor Sec. School - pix in school's technical office of (3?) winners." Otherwise the notes consist of a name of an event or location, followed by a request such as "several pics \& story," the first name of the staff who was assigned to cover it and, if necessary, a specific time of an event.

Files 2.1-2.8: Ledger Books by year

Item 2.1: 1975

Item 2.2: 1977

Item $2.3: 1978$

Item $2.4: 1979$

Item $2.5: 1980$

Item 2.6: 1981

Item $2.7: 1982$

Item $2.8: 1983$ 
THE CHATHAM DAILY NEWS COLLECTION CONTAINER LIST

\begin{tabular}{|c|c|c|c|c|c|c|c|}
\hline Box \# & Date Range & $\begin{array}{c}\text { \# of } \\
\text { Sleeves }\end{array}$ & $\begin{array}{c}\text { Shelf } \\
\text { Location }\end{array}$ & $\begin{array}{c}\text { Size of } \\
\text { Negatives }^{1}\end{array}$ & $\begin{array}{l}\text { Contact } \\
\text { Prints? }\end{array}$ & $\begin{array}{c}\text { Level of } \\
\text { Deterioration }{ }^{3}\end{array}$ & Notes \\
\hline 1 & 16 Feb.-12 Jun. 1946 & 86 & G4A & $4 \times 5^{\prime \prime}$ & & Level 1 & \\
\hline 2 & 13 Jun. - 2 Oct. 1946 & 95 & G4A & $4 \times 5^{\prime \prime}$ & & Level 1 & \\
\hline 3 & 3 Oct. 1946 - 15 Jan. 1947 & 87 & G4A & $4 \times 5^{\prime \prime}$ & & Level 1 & \\
\hline 4 & 13 Jan.-16 Apr. 1947 & 68 & G4A & $4 \times 5^{\prime \prime}$ & & Level 1 & \\
\hline 5 & 17 Apr.-23 Jul. 1947 & 79 & G4A & $4 \times 5^{\prime \prime}$ & & Level 1 & \\
\hline 6 & 21 Jul. 21-22 Oct. 22, 1947 & 79 & G4A & $4 \times 5^{\prime \prime}$ & & Level 1 & \\
\hline 7 & 20 Oct. 1947-24 Jan. 1948 & 84 & G4A & $4 \times 5^{\prime \prime}$ & & Level 1 & \\
\hline 8 & 22 Jan.-12 May 1948 & 81 & G4A & $4 \times 5^{\prime \prime}$ & & Level 1 & \\
\hline 9 & 13 May-4 Aug. 1948 & 81 & G4A & $4 \times 5^{\prime \prime}$ & & Level 1 & \\
\hline 10 & 5 Aug.-27 Oct. 1948 & 86 & G4A & $4 \times 5^{\prime \prime}$ & & Level 1 & \\
\hline 11 & 28 Oct. 1948-19 Feb. 1949 & 90 & G4B & $4 \times 5^{\prime \prime}$ & & Level 1 & \\
\hline 12 & 21 Feb.-1 Jun. 1949 & 86 & G4B & $4 \times 5^{\prime \prime}$ & & Level 1 & \\
\hline 13 & 2 Jun.- 17 Aug. 1949 & 88 & G4B & $4 \times 5^{\prime \prime}$ & & Level 1 & \\
\hline 14 & 18 Aug.- 29 Oct. 1949 & 63 & G4B & $4 \times 5^{\prime \prime}$ & & Level 1 & \\
\hline 15 & 27 Oct. 1949-28 Jan. 1950 & 87 & G4B & $4 \times 5^{\prime \prime}$ & & Level 1 & \\
\hline 16 & 30 Jan.-19 Apr. 1950 & 100 & G4B & $4 \times 5^{\prime \prime}$ & & Level 1 & \\
\hline 17 & 17 Apr.-21 Jun. 1950 & 81 & G4B & $4 \times 5^{\prime \prime}$ & & Level 1 & \\
\hline 18 & 19 Jun.-30 Aug. 1950 & 74 & G4B & $4 \times 5^{\prime \prime}$ & & Level 1 & \\
\hline 19 & 28 Aug.-28 Oct. 1950 & 71 & G4B & $4 \times 5^{\prime \prime}$ & & Level 1 & \\
\hline 20 & 26 Oct. 1950-6 Jan. 1951 & 75 & G4B & $4 \times 5^{\prime \prime}$ & & Level 1 & \\
\hline 21 & 8 Jan.-7 Apr. 1951 & 61 & G4B & $4 \times 5^{\prime \prime}$ & & Level 1 & \\
\hline 22 & 5 Apr.-23 Jun. 1951 & 52 & G4B & $4 \times 5^{\prime \prime}$ & & Level 2 & \\
\hline
\end{tabular}




\begin{tabular}{|c|c|c|c|c|c|}
\hline 23 & 23 Jun.-8 Sept. 1951 & 67 & G4B & $4 \times 5^{\prime \prime}$ & Level 2 \\
\hline 24 & 10 Sept. 1951-12 Dec. 1951 & 65 & G4B & $4 \times 5^{\prime \prime}$ & Level 1 \\
\hline 25 & 13 Dec. 1951-26 Mar. 1952 & 59 & G4C & $4 \times 5^{\prime \prime}$ & Level 1 \\
\hline 26 & 27 Mar.-19 Jul. 1952 & 93 & G4C & $4 \times 5^{\prime \prime}$ & Level 1 \\
\hline 27 & 17 Jul.-12 Nov. 1952 & 68 & G4C & $4 \times 5^{\prime \prime}$ & Level 1 \\
\hline 28 & 10 Nov. 1952-13 Jun. 1953 & 69 & G4C & $4 \times 5^{\prime \prime}$ & Level 2 \\
\hline 29 & 11 Jun.-26 Aug. 1953 & 50 & G4C & $4 \times 5^{\prime \prime}$ & Level 1 \\
\hline 30 & 24 Aug.- Nov. 5, 1953 & 50 & G4C & $4 \times 5^{\prime \prime}$ & Level 1 \\
\hline 31 & 5 Nov. 1953-9 Jan. 1954 & 56 & G4C & $4 \times 5 "$ & Level 1 \\
\hline 32 & 11 Jan.-27 Feb. 1954 & 74 & G4C & $4 \times 5^{\prime \prime}, 6 \times 6 \mathrm{~cm}$ & Level 1 \\
\hline 33 & 25 Feb.-28 Apr. 1954 & 68 & G4C & $4 \times 5^{\prime \prime}, 6 \times 6 \mathrm{~cm}$ & Level 2 \\
\hline 34 & 26 Apr.-19 Jun. 1954 & 85 & G4C & $4 \times 5^{\prime \prime}, 6 \times 6 \mathrm{~cm}$ & Level 1 \\
\hline 35 & 21 Jun.-18 Aug. 1954 & 104 & G4C & $4 \times 5^{\prime \prime}, 6 \times 6 \mathrm{~cm}$ & Level 1 \\
\hline 36 & 16 Aug.-16 Oct. 1954 & 93 & G4C & $4 \times 5^{\prime \prime}, 6 \times 6 \mathrm{~cm}$ & Level 1 \\
\hline 37 & 16 Oct.-18 Dec. 1954 & 90 & G4C & $4 \times 5^{\prime \prime}, 6 \times 6 \mathrm{~cm}$ & Level 1 \\
\hline 38 & 18 Dec. 1954-2 Mar. 1955 & 59 & G4C & $4 \times 5^{\prime \prime}, 6 \times 6 \mathrm{~cm}$ & Level 1 \\
\hline 39 & 3 Mar.-14 May 1955 & 65 & G4C & $4 \times 5^{\prime \prime}, 6 \times 6 \mathrm{~cm}$ & Level 1 \\
\hline 40 & 16 May-17 Aug. 1955 & 73 & G4D & $4 \times 5^{\prime \prime}, 6 \times 6 \mathrm{~cm}$ & Level 1 \\
\hline 41 & 15 Aug.-26 Oct. 1955 & 85 & G4D & $4 \times 5^{\prime \prime}, 6 \times 6 \mathrm{~cm}$ & Level 1 \\
\hline 42 & 24 Oct. 1935-14 Jan. 1956 & 67 & G4D & $4 \times 5^{\prime \prime}, 6 \times 6 \mathrm{~cm}$ & Level 2 \\
\hline 43 & 16 Jan.-4 Apr. 1956 & 55 & G4D & $4 \times 5^{\prime \prime}, 6 \times 6 \mathrm{~cm}$ & Level 2 \\
\hline 44 & 2 Apr.-23 May 1956 & 51 & G4D & $4 \times 5^{\prime \prime}, 6 \times 6 \mathrm{~cm}$ & Level 1 \\
\hline 45 & 24 May-7 Jul. 1956 & 71 & G4D & $4 \times 5^{\prime \prime}, 6 \times 6 \mathrm{~cm}$ & Level 1 \\
\hline 46 & 5 Jul.-6 Oct. 1956 & 57 & G4D & $4 \times 5^{\prime \prime}, 6 \times 6 \mathrm{~cm}$ & Level 1 \\
\hline 47 & 8 Oct. 1956-27 Feb. 1957 & 87 & G4D & $4 \times 5^{\prime \prime}, 6 \times 6 \mathrm{~cm}$ & Level 2 \\
\hline 48 & 25 Feb.-10 Jul. 1957 & 100 & G4D & $4 \times 5^{\prime \prime}, 6 \times 6 \mathrm{~cm}$ & Level 1 \\
\hline 49 & 11 Jul.-11 Dec. 1957 & 128 & G4D & $6 \times 6 \mathrm{~cm}, 4 \times 5 "$ & Level 1 \\
\hline
\end{tabular}




\begin{tabular}{|c|c|c|c|c|c|c|}
\hline 50 & 13 Dec. 1957-16 May 1958 & 139 & G4D & $6 \times 6 \mathrm{~cm}, 4 \times 5 "$ & Level 1 & \\
\hline 51 & 17 May-7 Aug. 1958 & 138 & G4D & $6 \times 6 \mathrm{~cm}, 4 \times 5 "$ & Level 3 & \\
\hline 52 & 8 Aug.-15 Oct. 1958 & 108 & G4D & $4 \times 5^{\prime \prime}, 6 \times 6 \mathrm{~cm}$ & Level 6 & \\
\hline 53 & 16 Oct.-12 Dec. 1958 & 90 & G4D & $4 \times 5^{\prime \prime}, 6 \times 6 \mathrm{~cm}$ & Level 1 & \\
\hline 54 & 13 Dec. 1958-11 Feb. 1959 & 73 & G4D & $4 \times 5^{\prime \prime}, 6 \times 6 \mathrm{~cm}$ & Level 1 & \\
\hline 55 & 12 Feb.-4 Apr. 1959 & 66 & G4E & $4 \times 5^{\prime \prime}, 6 \times 6 \mathrm{~cm}$ & Level 1 & \\
\hline 56 & 6 Apr.-1 Jun. 1959 & 67 & G4E & $4 \times 5^{\prime \prime}$ & Level 1 & \\
\hline 57 & 2 Jun.-25 Jul. 1959 & 61 & G4E & $4 \times 5^{\prime \prime}$ & Level 1 & $\begin{array}{l}\text { Royal } \\
\text { Visit, } 03 \\
\text { July, } \\
1959\end{array}$ \\
\hline 58 & 27 Jul.-23 Sept. 1959 & 64 & G4E & $4 \times 5^{\prime \prime}$ & Level 1 & \\
\hline 59 & 24 Sept.-6 Nov. 1959 & 76 & G4E & $4 \times 5^{\prime \prime}$ & Level 1 & \\
\hline 60 & 7 Nov.-24 Dec. 1959 & 82 & G4E & $4 \times 5^{\prime \prime}$ & Level 1 & \\
\hline 61 & 24 Dec. 1959-19 Feb. 1960 & 74 & G4E & $4 \times 5^{\prime \prime}$ & Level 2 & \\
\hline 62 & 20 Feb.-4 Apr. 1960 & 107 & G4E & $4 \times 5^{\prime \prime}$ & Level 1 & \\
\hline 63 & 5 Apr. 5-16 May 1960 & 72 & G4E & $4 \times 5^{\prime \prime}, 6 \times 6 \mathrm{~cm}$ & Level 1 & \\
\hline 64 & 16 May-21 Jun. 1960 & 79 & G4E & $4 \times 5^{\prime \prime}, 6 \times 6 \mathrm{~cm}$ & Level 6 & \\
\hline 65 & 22 Jun.-25 Jul. 1960 & 55 & G4E & $4 \times 5^{\prime \prime}, 6 \times 6 \mathrm{~cm}$ & Level 6 & \\
\hline 66 & 26 Jul.-10 Sept. 1960 & 83 & G4E & $4 \times 5^{\prime \prime}, 6 \times 6 \mathrm{~cm}$ & Level 6 & \\
\hline 67 & 10 Sept.-27 Oct. 1960 & 77 & G4E & $4 \times 5^{\prime \prime}, 6 \times 6 \mathrm{~cm}$ & Level 6 & \\
\hline 68 & 25 Oct.-21 Dec. 1960 & 85 & G4E & $4 \times 5^{\prime \prime}, 6 \times 6 \mathrm{~cm}$ & Level 6 & \\
\hline 69 & 22 Dec. 1960-16 Feb. 1961 & 75 & G4E & $4 \times 5^{\prime \prime}, 6 \times 6 \mathrm{~cm}$ & Level 6 & \\
\hline 70 & 3 Jan.-23 Feb. 1961 & 100 & G4F & $4 \times 5^{\prime \prime}, 6 \times 6 \mathrm{~cm}$ & Level 1 & \\
\hline 71 & 17 Feb.-30 Mar. 1961 & 76 & G4F & $4 \times 5^{\prime \prime}, 6 \times 6 \mathrm{~cm}$ & Level 6 & \\
\hline 72 & 1 Apr.-17 May 1961 & 62 & G4F & $4 \times 5^{\prime \prime}, 6 \times 6 \mathrm{~cm}$ & Level 6 & \\
\hline 73 & 18 May-3 Jul. 1961 & 67 & G4F & $4 \times 5^{\prime \prime}, 6 \times 6 \mathrm{~cm}$ & Level 1 & \\
\hline
\end{tabular}




\begin{tabular}{|c|c|c|c|c|c|}
\hline 74 & 4 Jul.-2 Sept. 1961 & 100 & G4F & $4 \times 5^{\prime \prime}, 6 \times 6 \mathrm{~cm}$ & Level 1 \\
\hline 75 & 5 Sept.-3 Nov. 1961 & 102 & G4F & $4 \times 5^{\prime \prime}, 6 \times 6 \mathrm{~cm}$ & Level 4 \\
\hline 76 & 4 Nov. 1961-2 Jan. 1962 & 103 & G4F & $4 \times 5 ", 6 \times 6 \mathrm{~cm}$ & Level 4 \\
\hline 77 & 24 Feb.-16 Apr. 1962 & 109 & G4F & $4 \times 5^{\prime \prime}, 6 \times 6 \mathrm{~cm}$ & Level 1 \\
\hline 78 & 17 Apr.-7 Jun. 1962 & 112 & G4F & $4 \times 5^{\prime \prime}, 6 \times 6 \mathrm{~cm}$ & Level 1 \\
\hline 79 & 8 Jun.-26 Jul. 1962 & 92 & G4F & $4 \times 5^{\prime \prime}, 6 \times 6 \mathrm{~cm}$ & Level 1 \\
\hline 80 & 27 Jul.-17 Sept. 1962 & 90 & G4F & $4 \times 5^{\prime \prime}, 6 \times 6 \mathrm{~cm}$ & Level 1 \\
\hline 81 & 18 Sept.-24 Oct. 1962 & 81 & G4F & $4 \times 5^{\prime \prime}, 6 \times 6 \mathrm{~cm}$ & Level 1 \\
\hline 82 & 25 Oct.-5 Dec. 1962 & 83 & G4F & $4 \times 5^{\prime \prime}, 6 \times 6 \mathrm{~cm}$ & Level 1 \\
\hline 83 & 6 Dec. 1962-24 Jan. 1963 & 90 & G4F & $4 \times 5^{\prime \prime}, 6 \times 6 \mathrm{~cm}$ & Level 1 \\
\hline 84 & 26 Jan.-6 Mar. 1963 & 91 & G4F & $4 \times 5^{\prime \prime}, 6 \times 6 \mathrm{~cm}$ & Level 1 \\
\hline 85 & 7 Mar.-16 Apr. 1963 & 96 & G4G & $4 \times 5^{\prime \prime}, 6 \times 6 \mathrm{~cm}$ & Level 1 \\
\hline 86 & 17 Apr.-31 May 1963 & 97 & G4G & $4 \times 5^{\prime \prime}, 6 \times 6 \mathrm{~cm}$ & Level 1 \\
\hline 87 & 1 Jun.-23 Jul. 1963 & 94 & G4G & $4 \times 5 ", 6 \times 6 \mathrm{~cm}$ & Level 1 \\
\hline 88 & 24 Jul.-20 Sept. 1963 & 107 & G4G & $4 \times 5^{\prime \prime}, 6 \times 6 \mathrm{~cm}$ & Level 1 \\
\hline 89 & 21 Sept.-6 Nov. 1963 & 95 & G4G & $4 \times 5^{\prime \prime}, 6 \times 6 \mathrm{~cm}$ & Level 1 \\
\hline 90 & 7 Nov.-28 Dec. 1963 & 95 & G4G & $4 \times 5^{\prime \prime}, 6 \times 6 \mathrm{~cm}$ & Level 1 \\
\hline 91 & 30 Dec. 1963-13 Feb. 1964 & 91 & G4G & $4 \times 5^{\prime \prime}, 6 \times 6 \mathrm{~cm}$ & Level 1 \\
\hline 92 & 14 Feb.-30 Mar. 1964 & 93 & G4G & $4 \times 5^{\prime \prime}, 6 \times 6 \mathrm{~cm}$ & Level 1 \\
\hline 93 & 31 Mar. -25 May 1964 & 103 & G4G & $4 \times 5^{\prime \prime}, 6 \times 6 \mathrm{~cm}$ & Level 1 \\
\hline 94 & 26 May-14 Jul. 1964 & 97 & G4G & $4 \times 5^{\prime \prime}, 6 \times 6 \mathrm{~cm}$ & Level 1 \\
\hline 95 & 15 Jul.-5 Sept. 1964 & 94 & G4G & $4 \times 5^{\prime \prime}, 6 \times 6 \mathrm{~cm}$ & Level 1 \\
\hline 96 & 5 Sept.-22 Oct.1964 & 89 & G4G & $4 \times 5^{\prime \prime}, 6 \times 6 \mathrm{~cm}$ & Level 1 \\
\hline 97 & 23 Oct.-12 Dec. 1964 & 81 & G4G & $4 \times 5^{\prime \prime}, 6 \times 6 \mathrm{~cm}$ & Level 1 \\
\hline 98 & 14 Dec. 1964-29 Jan. 1965 & 89 & G4G & $4 \times 5^{\prime \prime}, 6 \times 6 \mathrm{~cm}$ & Level 1 \\
\hline 99 & 30 Jan.-3 Mar. 1965 & 78 & G4G & $4 \times 5^{\prime \prime}, 6 \times 6 \mathrm{~cm}$ & Level 1 \\
\hline 100 & 4 Mar.-14 Apr. 1965 & 82 & G3A & $4 \times 5^{\prime \prime}, 6 \times 6 \mathrm{~cm}$ & Level 1 \\
\hline
\end{tabular}




\begin{tabular}{|c|c|c|c|c|c|}
\hline 101 & 15 Apr.-28 May 1965 & 79 & G3A & $4 \times 5^{\prime \prime}, 6 \times 6 \mathrm{~cm}$ & Level 1 \\
\hline 102 & 29 May-12 Jul. 1965 & 84 & G3A & $4 \times 5^{\prime \prime}$ & Level 1 \\
\hline 103 & 13 Jul.-8 Sept. 1965 & 98 & G3A & $4 \times 5^{\prime \prime}$ & Level 1 \\
\hline 104 & 9 Sept.-30 Oct. 1965 & 93 & G3A & $4 \times 5^{\prime \prime}$ & Level 1 \\
\hline 105 & 1 Nov.-31 Dec. 1965 & 111 & G3A & $4 \times 5^{\prime \prime}$ & Level 1 \\
\hline 106 & 3 Jan.-17 Mar 1966 & 129 & G3A & $4 \times 5^{\prime \prime}$ & Level 1 \\
\hline 107 & 18 Mar.-24 May 1966 & 111 & G3A & $4 \times 5^{\prime \prime}$ & Level 1 \\
\hline 108 & 25 May-11 Aug. 1966 & 124 & G3A & $4 \times 5^{\prime \prime}$ & Level 1 \\
\hline 109 & 12 Aug.-27 Oct. 1966 & 113 & G3A & $4 \times 5^{\prime \prime}$ & Level 1 \\
\hline 110 & 28 Oct. 1966-6 Jan. 1967 & 115 & G3B & $4 \times 5^{\prime \prime}$ & Level 1 \\
\hline 111 & 7 Jan.-27 Mar. 1967 & 130 & G3B & $4 \times 5^{\prime \prime}$ & Level 1 \\
\hline 112 & Mar. 28-Jun. 19, 1967 & 110 & G3B & $4 \times 5^{\prime \prime}$ & Level 1 \\
\hline 113 & 20 Jun.-12 Sept. 1967 & 75 & G3B & $6 \times 6 \mathrm{~cm}$ & Level 1 \\
\hline 114 & 13 Sept.-26 Dec. 1967 & 94 & G3B & $6 \times 6 \mathrm{~cm}$ & Level 1 \\
\hline 115 & 27 Dec. 1967-1 Apr. 1968 & 82 & G3B & $6 \times 6 \mathrm{~cm}$ & Level 1 \\
\hline 116 & 2 Apr. 2-27 Jun. 1968 & 74 & G3B & $6 \times 6 \mathrm{~cm}$ & Level 1 \\
\hline 117 & 28 Jun.-25 Sept. 1968 & 73 & G3B & $6 \times 6 \mathrm{~cm}$ & Level 1 \\
\hline 118 & 26 Sept.-26 Dec. 1968 & 77 & G3B & $6 \times 6 \mathrm{~cm}$ & Level 1 \\
\hline 119 & 27 Dec. 1968-10 Apr. 1969 & 92 & G3B & $6 \times 6 \mathrm{~cm}$ & Level 1 \\
\hline 120 & 11 Apr.-26 Jul. 1969 & 89 & G3B & $6 \times 6 \mathrm{~cm}$ & Level 1 \\
\hline 121 & 28 Jul. -5 Nov. 1969 & 83 & G3B & $6 \times 6 \mathrm{~cm}$ & Level 1 \\
\hline 122 & 6 Nov. 1969-3 Feb. 1970 & 75 & G3B & $6 \times 6 \mathrm{~cm}$ & Level 1 \\
\hline 123 & 4 Feb.-12 May 1970 & 85 & G3B & $6 \times 6 \mathrm{~cm}$ & Level 1 \\
\hline 124 & 13 May-18 Aug. 1970 & 79 & G3B & $6 \times 6 \mathrm{~cm}$ & Level 1 \\
\hline 125 & 19 Aug.-12 Dec. 1970 & 93 & G3C & $6 \times 6 \mathrm{~cm}$ & Level 1 \\
\hline 126 & 14 Dec. 1970-7 Apr. 1971 & 97 & G3C & $6 \times 6 \mathrm{~cm}$ & Level 1 \\
\hline 127 & 8 Apr.-23 Jul. 1971 & 88 & G3C & $6 \times 6 \mathrm{~cm}$ & Level 1 \\
\hline
\end{tabular}




\begin{tabular}{|c|c|c|c|c|c|}
\hline 128 & 24 Jul.-9 Nov. 1971 & 91 & G3C & $6 \times 6 \mathrm{~cm}$ & Level 1 \\
\hline 129 & 10 Nov. 1971-18 Feb. 1972 & 95 & G3C & $6 \times 6 \mathrm{~cm}$ & Level 1 \\
\hline 130 & 19 Feb.-3 Jun. 1972 & 89 & G3C & $6 \times 6 \mathrm{~cm}$ & Level 1 \\
\hline 131 & 5 Jun.-17 Sept. 1972 & 91 & G3C & $6 \times 6 \mathrm{~cm}$ & Level 1 \\
\hline 132 & 19 Sept.-30 Dec. 1972 & 85 & G3C & $6 \times 6 \mathrm{~cm}$ & Level 1 \\
\hline 133 & 2 Jan.-9 Apr. 1973 & 78 & G3C & $6 \times 6 \mathrm{~cm}$ & Level 1 \\
\hline 134 & 10 Apr.-30 Jun. 1973 & 68 & G3C & $6 \times 6 \mathrm{~cm}$ & Level 1 \\
\hline 135 & 3 Jul.-5 Oct. 1973 & 98 & G3C & $6 \times 6 \mathrm{~cm}$ & Level 1 \\
\hline 136 & 9 Oct. 1973-5 Feb. 1974 & 106 & G3C & $6 \times 6 \mathrm{~cm}$ & Level 1 \\
\hline 137 & 6 Feb.-18 May 1974 & 89 & G3C & $6 \times 6 \mathrm{~cm}$ & Level 1 \\
\hline 138 & 21 May-16 Sept. 1974 & 99 & G3C & $6 \times 6 \mathrm{~cm}$ & Level 1 \\
\hline 139 & 17 Sept. 1974-9 Jan. 1975 & 102 & G3C & $6 \times 6 \mathrm{~cm}$ & Level 1 \\
\hline 140 & 10 Jan.-5 May 1975 & 97 & G3D & $6 \times 6 \mathrm{~cm}$ & Level 1 \\
\hline 141 & 6 May-23 Aug. 1975 & 93 & G3D & $6 \times 6 \mathrm{~cm}$ & Level 1 \\
\hline 142 & 25 Aug.-12 Dec. 1975 & 93 & G3D & $6 \times 6 \mathrm{~cm}$ & Level 1 \\
\hline 143 & 13 Dec. 1975-3 Apr. 1976 & 111 & G3D & $6 \times 6 \mathrm{~cm}$ & Level 1 \\
\hline 144 & 3 Apr.-10 Jul. 1976 & 163 & G3D & $6 \times 6 \mathrm{~cm}$ & Level 1 \\
\hline 145 & 12 Jul. -25 Oct. 1976 & 104 & G3D & $6 \times 6 \mathrm{~cm}$ & Level 1 \\
\hline 146 & 26 Oct. 1976-1 Feb. 1977 & 109 & G3D & $6 \times 6 \mathrm{~cm}$ & Level 1 \\
\hline 147 & 2 Feb.-4 May 1977 & 149 & G3D & $6 \times 6 \mathrm{~cm}$ & Level 1 \\
\hline 148 & 5 May-2 Aug. 1977 & 122 & G3D & $6 \times 6 \mathrm{~cm}$ & Level 1 \\
\hline 149 & 2 Aug.-29 Oct. 1977 & 137 & G3D & $6 \times 6 \mathrm{~cm}$ & Level 1 \\
\hline 150 & 31 Oct. 1977-1 Feb. 1978 & 127 & G3D & $6 \times 6 \mathrm{~cm}$ & Level 1 \\
\hline 151 & 2 Feb.-19 May 1978 & 87 & G3D & $35 \mathrm{~mm}$ & Level 1 \\
\hline 152 & 20 May-21 Aug 1978 & 75 & G3D & $35 \mathrm{~mm}$ & Level 1 \\
\hline 153 & 22 Aug.-25 Nov. 1978 & 78 & G3D & $35 \mathrm{~mm}$ & Level 1 \\
\hline 154 & 27 Nov. 1978-10 Mar. 1979 & 91 & G3D & $35 \mathrm{~mm}$ & Level 1 \\
\hline
\end{tabular}




\begin{tabular}{|c|c|c|c|c|c|c|}
\hline 155 & 12 Mar.-17 May 1979 & 63 & G3D & $35 \mathrm{~mm}$ & & Level 1 \\
\hline 156 & 18 May-30 Jun. 1979 & 44 & G3E & $35 \mathrm{~mm}$ & $\sqrt{ }$ & Level 1 \\
\hline 157 & 3 Jul.-15 Aug. 1979 & 40 & G3E & $35 \mathrm{~mm}$ & $\sqrt{ }$ & Level 1 \\
\hline 158 & 16 Aug.-12 Oct. 1979 & 52 & G3E & $35 \mathrm{~mm}$ & $\sqrt{ }$ & Level 1 \\
\hline 159 & 13 Oct.-28 Dec. 1979 & 68 & G3E & $35 \mathrm{~mm}$ & $\sqrt{ }$ & Level 1 \\
\hline 160 & 29 Dec. 1979-15 Feb. 1980 & 42 & G3E & $35 \mathrm{~mm}$ & $\sqrt{ }$ & Level 1 \\
\hline 161 & 16 Feb.-2 Apr. 1980 & 41 & G3E & $35 \mathrm{~mm}$ & $\sqrt{ }$ & Level 1 \\
\hline 162 & 3 Apr.-23 May 1980 & 42 & G3E & $35 \mathrm{~mm}$ & $\sqrt{ }$ & Level 1 \\
\hline 163 & 24 May-25 Jul. 1980 & 53 & G3E & $35 \mathrm{~mm}$ & $\sqrt{ }$ & Level 1 \\
\hline 164 & 24 Jul.-29 Sept. 1980 & 61 & G3E & $35 \mathrm{~mm}$ & $\checkmark$ & Level 1 \\
\hline 165 & 30 Sept.-8 Dec. 1980 & 59 & G3E & $35 \mathrm{~mm}$ & $\sqrt{ }$ & Level 1 \\
\hline 166 & 15 Dec. 1980-28 Jan. 1981 & 46 & G3E & $35 \mathrm{~mm}$ & $\sqrt{ }$ & Level 1 \\
\hline 167 & 29 Jan.-10 Mar. 1981 & 40 & G3E & $35 \mathrm{~mm}$ & $\sqrt{ }$ & Level 1 \\
\hline 168 & 11 Mar.-21 Apr. 1981 & 36 & G3E & $35 \mathrm{~mm}$ & $\sqrt{ }$ & Level 1 \\
\hline 169 & 22 Apr.-4 Jun. 1981 & 36 & G3E & $35 \mathrm{~mm}$ & $\sqrt{ }$ & Level 1 \\
\hline 170 & 5 Jun.-22 Jul. 1981 & 41 & G3E & $35 \mathrm{~mm}$ & $\sqrt{ }$ & Level 1 \\
\hline 171 & 23 Jul.-12 Sept. 1981 & 43 & G3F & $35 \mathrm{~mm}$ & $\checkmark$ & Level 1 \\
\hline 172 & 14 Sept.-5 Nov. 1981 & 45 & G3F & $35 \mathrm{~mm}$ & $\sqrt{ }$ & Level 1 \\
\hline 173 & 6 Nov.-31 Dec. 1981 & 47 & G3F & $35 \mathrm{~mm}$ & $\sqrt{ }$ & Level 1 \\
\hline 174 & 2 Jan.-25 Mar. 1982 & 65 & G3F & $35 \mathrm{~mm}$ & $\sqrt{ }$ & Level 1 \\
\hline 175 & 26 Mar.-26 May 1982 & 50 & G3F & $35 \mathrm{~mm}$ & $\sqrt{ }$ & Level 1 \\
\hline 176 & 27 May-28 Jul. 1982 & 51 & G3F & $35 \mathrm{~mm}$ & $\sqrt{ }$ & Level 1 \\
\hline 177 & 29 Jul.-2 Oct. 1982 & 56 & G3F & $35 \mathrm{~mm}$ & $\sqrt{ }$ & Level 1 \\
\hline 178 & 4 Oct.-1 Dec. 1982 & 50 & G3F & $35 \mathrm{~mm}$ & $\sqrt{ }$ & Level 1 \\
\hline 179 & 2 Dec. 1982-3 Feb. 1983 & 53 & G3F & $35 \mathrm{~mm}$ & $\sqrt{ }$ & Level 1 \\
\hline 180 & 7 Feb.-9 Apr. 1983 & 53 & G3F & $35 \mathrm{~mm}$ & $\sqrt{ }$ & Level 1 \\
\hline 181 & 11 Apr.-27 May 1983 & 39 & G3F & $35 \mathrm{~mm}$ & $\sqrt{ }$ & Level 1 \\
\hline
\end{tabular}




\begin{tabular}{|c|c|c|c|c|c|c|}
\hline 182 & 28 May-18 Jul. 1983 & 44 & G3F & $35 \mathrm{~mm}$ & $\sqrt{ }$ & Level 1 \\
\hline 183 & 19 Jul.-8 Sept. 1983 & 44 & G3F & $35 \mathrm{~mm}$ & $\sqrt{ }$ & Level 1 \\
\hline 184 & 9 Sept.-2 Nov. 1983 & 46 & G3F & $35 \mathrm{~mm}$ & $\sqrt{ }$ & Level 1 \\
\hline 185 & 3 Nov.-27 Dec. 1983 & 45 & G3F & $35 \mathrm{~mm}$ & $\sqrt{ }$ & Level 1 \\
\hline 186 & 28 Dec. 1983-18 Feb. 1984 & 45 & G3G & $35 \mathrm{~mm}$ & $\sqrt{ }$ & Level 1 \\
\hline 187 & 20 Feb.-9 Apr. 1984 & 43 & G3G & $35 \mathrm{~mm}$ & $\sqrt{ }$ & Level 1 \\
\hline 188 & 10 Apr.-28 May 1984 & 41 & G3G & $35 \mathrm{~mm}$ & $\sqrt{ }$ & Level 1 \\
\hline 189 & 29 May-18 Jul. 1984 & 42 & G3G & $35 \mathrm{~mm}$ & $\sqrt{ }$ & Level 1 \\
\hline 190 & 19 Jul.-12 Sept. 1984 & 49 & G3G & $35 \mathrm{~mm}$ & $\sqrt{ }$ & Level 1 \\
\hline 191 & 13 Sept.-6 Nov. 1984 & 47 & G3G & $35 \mathrm{~mm}$ & $\checkmark$ & Level 1 \\
\hline 192 & 7 Nov. 1984-7 Jan. 1985 & 53 & G3G & $35 \mathrm{~mm}$ & $\sqrt{ }$ & Level 1 \\
\hline 193 & 6 Jan.-12 Mar. 1985 & 52 & G3G & $35 \mathrm{~mm}$ & $\sqrt{ }$ & Level 1 \\
\hline 194 & 13 Mar.-30 Apr. 1985 & 39 & G3G & $35 \mathrm{~mm}$ & $\checkmark$ & Level 1 \\
\hline 195 & 1 May-12 Jun. 1985 & 36 & G3G & $35 \mathrm{~mm}$ & $\sqrt{ }$ & Level 1 \\
\hline 196 & 13 Jun.-26 Jul. 1985 & 36 & G3G & $35 \mathrm{~mm}$ & $\sqrt{ }$ & Level 1 \\
\hline 197 & 26 Jul.-17 Sept. 1985 & 42 & G3G & $35 \mathrm{~mm}$ & $\sqrt{ }$ & Level 1 \\
\hline 198 & 18 Sept.-1 Nov. 1985 & 37 & G3G & $35 \mathrm{~mm}$ & $\sqrt{ }$ & Level 1 \\
\hline 199 & 2 Nov.-16 Dec. 1985 & 41 & G3G & $35 \mathrm{~mm}$ & $\sqrt{ }$ & Level 1 \\
\hline 200 & 17 Dec. 1985-11 Feb. 1986 & 46 & G3G & $35 \mathrm{~mm}$ & $\sqrt{ }$ & Level 1 \\
\hline 201 & 12 Feb.-5 Apr. 1986 & 41 & G2A & $35 \mathrm{~mm}$ & $\sqrt{ }$ & Level 1 \\
\hline 202 & 7 Apr.-24 Jun. 1986 & 39 & G2A & $35 \mathrm{~mm}$ & $\sqrt{ }$ & Level 1 \\
\hline 203 & 25 Jun. 1986-7 Mar. 1987 & 42 & G2A & $35 \mathrm{~mm}$ & $\sqrt{ }$ & Level 1 \\
\hline 204 & 9 Mar.-27 Apr. 1987 & 39 & G2A & $35 \mathrm{~mm}$ & $\checkmark$ & Level 1 \\
\hline 205 & 28 Apr.-12 Jun. 1987 & 35 & G2A & $35 \mathrm{~mm}$ & $\checkmark$ & Level 1 \\
\hline 206 & 13 Jun. 1987-24 Jul. 1987 & 36 & G2A & $35 \mathrm{~mm}$ & $\sqrt{ }$ & Level 1 \\
\hline 207 & 25 Jul.-15 Sept. 1987 & 43 & G2A & $35 \mathrm{~mm}$ & $\sqrt{ }$ & Level 1 \\
\hline 208 & 17 Sept. 1987-31 Oct. 1987 & 36 & G2A & $35 \mathrm{~mm}$ & $\sqrt{ }$ & Level 1 \\
\hline
\end{tabular}




\begin{tabular}{|c|c|c|c|c|c|c|}
\hline 209 & 1 Nov. 1987-30 Nov. 1987 & 25 & G2A & $35 \mathrm{~mm}$ & $\sqrt{ }$ & Level 1 \\
\hline 210 & Miscellaneous & & G2B & $35 \mathrm{~mm}$ & $\checkmark$ & Level 1 \\
\hline 211 & Misc Pics by Subject & & G2B & $4 \times 5^{\prime \prime}, 6 \times 6 \mathrm{~cm}$ & & Level 1 \\
\hline \multirow[t]{9}{*}{212} & Disasters \& Accidents & & G2B & $4 \times 5^{\prime \prime}, 6 \times 6 \mathrm{~cm}$ & & Level 1 \\
\hline & Ledger book - 1975 & & G2B & ca. 400 pages & N/A & $\mathrm{N} / \mathrm{A}$ \\
\hline & Ledger book - 1977 & & G2B & ca. 400 pages & N/A & $\mathrm{N} / \mathrm{A}$ \\
\hline & Ledger book - 1978 & & G2B & ca. 400 pages & N/A & $\mathrm{N} / \mathrm{A}$ \\
\hline & Ledger book - 1979 & & G2B & ca. 400 pages & N/A & $\mathrm{N} / \mathrm{A}$ \\
\hline & Ledger book - 1980 & & G2B & ca. 400 pages & N/A & $\mathrm{N} / \mathrm{A}$ \\
\hline & Ledger book - 1981 & & G2B & ca. 400 pages & N/A & $\mathrm{N} / \mathrm{A}$ \\
\hline & Ledger book - 1982 & & G2B & ca. 400 pages & N/A & $\mathrm{N} / \mathrm{A}$ \\
\hline & Ledger book - 1983 & & G2B & ca. 400 pages & N/A & $\mathrm{N} / \mathrm{A}$ \\
\hline
\end{tabular}

\section{Levels of Deterioration ${ }^{4}$}

Level 1: No deterioration

Level 2: Negatives begin to curl at the edges and turn red or blue

Level 3: Negatives begin to shrink, become brittle and emit a vinegar odour

Level 4: Negatives begin to warp

Level 5: Bubbles and crystals begin to form in the film

Level 6: Channels begin to form in the film and the negatives turn blue

\footnotetext{
${ }^{1}$ Film types are listed in order from most to least common.

$2 \boldsymbol{V}$ indicates that there are contact prints with the negatives.
}

${ }^{3}$ Negatives were assessed using "A Short Guide to Film Base Photographic Materials: Identification, Care and Duplication" produced by the Northeast Document Conservation Centre.

4 "Preservation Leaflet 5.1 A Short Guide to Film Base Photographic Materials: Identification, Care, and Duplication." Northeast Document Conservation Center. 2012. Accessed May 5, 2015. https://www.nedcc.org/free-resources/preservation-leaflets/5.-photographs/5.1-ashort-guide-to-film-base-photographic-materials-identification,-care,-and-duplication. 


\section{Bibliography}

\section{Museum Management}

Buck, Rebecca A., and Jean Allman Gilmore, eds. MRM5: Museum Registration Methods. 5th ed. Washington, DC: AAM Press, American Association of Museums, 2010.

Hunter, Gregory S. Developing and Maintaining Practical Archives: A How-todo-it Manual. 2nd ed. New York: Neal-Schuman Publishers, 2003.

Keene, Suzanne. Fragments of the World: Uses of Museum Collections. Amsterdam: Elsevier Butterworth-Heinemann, 2005.

Matassa, Freda. Museum Collections Management: A Handbook. London: Facet Publishing, 2011.

Reibel, Daniel B. Registration Methods for the Small Museum. 4th ed. Lanham, MD.: AltaMira Press, 2008.

\section{Photographic Preservation}

Gorman, G. E., and Sydney J. Shep. Preservation Management for Libraries, Museums and Archives. London, UK: Facet Publishing, 2006.

"Preservation Leaflet 5.1 A Short Guide to Film Base Photographic Materials: Identification, Care, and Duplication." Northeast Document Conservation Center (2012). Accessed May 5, 2015. https://www.nedcc.org/freeresources/preservation-leaflets/5.-photographs/5.1-a-short-guide-to-filmbase-photographic-materials-identification,-care,-and-duplication.

Ritzenthaler, Mary Lynn, and Diane Connor. Photographs: Archival Care and Management. Chicago: Society of American Archivists, 2006. 


\section{Photojournalism \& The Press}

Brennen, Bonnie, and Hanno Hardt. Picturing the Past: Media, History, and Photography. Urbana: University of Illinois Press, 1999.

Fetherling, Douglas. The Rise of the Canadian Newspaper. Toronto: Oxford University Press Canada, 1990.

Freund, Gisèle. Photography \& Society. Boston: D.R. Godine, 1980.

Frizot, Michel. "Close Witnesses: The Involvement of the Photojournalist." In A New History of Photography, 591-611. Koln: Konemann, 1998.

Glazebrook, G. P. De T. Life in Ontario: A Social History. Toronto: University of Toronto Press, 1975.

Hill, Jason E., and Vanessa R. Schwartz, eds. Getting the Picture: The Visual Culture of the News. 1st ed. London: Bloomsbury, 2015.

Kesterton, Wilfred H. A History of Journalism in Canada. Toronto: McClelland and Stewart Limited, 1967.

Komorous, Hana. Canadian Newspapers: The Record of Our Past, The Mirror of Our Time: Proceedings of the Second National Newspapers Colloquium, Vancouver, British Columbia, June 11,1987. Ottawa: National Library of Canada, 1989. Print.

Lauriston, Victor. Romantic Kent: The Story of a County 1626-1952. Chatham, ON: Corporation of the County of Kent, 1952.

Marien, Mary Warner. "Art and the Age of Mass Media: Photojournalism." In Photography: A Cultural History, 235-238. 3rd ed. Upper River Saddle, NJ: Prentice Hall, 2011.

Newhall, Beaumont. "Photojournalism." In The History of Photography: From 1839 to the Present, 249-267. Completely Rev. and Enl. ed. New York: Museum of Modern Art;; 1982. 
Nichols, Mark Edgar. (CP) The Story of the Canadian Press. Toronto: Ryerson Press, 1948.

Panzer, Mary. "The Meaning of the Twentieth-Century Press Archive." Aperture 2011: 46. Print.

Panzer, Mary. Things As They Are: Photojournalism in Context Since 1955. New York: Aperture, 2005.

Rosenblum, Naomi. "Words and Pictures: Photographs in Print Media, 19201980." In A World History of Photography, 462-515. 3rd ed. New York, NY: Abbeville Press, 1997.

Szarkowski, John, ed. From the Picture Press. New York: Museum of Modern Art, 1973.

"The Evolution of Newspapers." Newspapers Canada, (November 12, 2014). Accessed January 4, 2015. http://www.newspaperscanada.ca/aboutnewspapers/history-newspapers.

Von Dewitz, Bodo, ed., Robert Lebeck, comp., Kiosk: A History of

Photojournalism, 1839-1973. Gottingen: Steidl, 2001.

\section{Archival Description and Arrangement}

Canadian Archival Standard Rules for Archival Description. Ottawa: Bureau of Canadian Archivists, 2008.

Carmichael, David W. Organizing Archival Records. Maryland: AltaMira Press, 2012.

Casper, Sara. "Creating Finding Aids." South Dakota State Historical Society. South Dakota State Historical Society. Web. 12 Nov. 2014. $<$ https://history.sd.gov/Archives/.../Creating Finding Aids.ppt>. 
Cox, Richard J. "Revisiting the Archival Finding Aid." Journal of Archival Organization. Vol. 5, no. 4 (2008): 5-32. Accessed January 28, 2015. http://d-scholarship.pitt.edu/2685/

Evans, Hilary. Practical Picture Research: A Guide to Current Practice, Procedure, Techniques, and Resources. London: Blueprint, 1992.

Fox, Michael J., and Peter L. Wilkerson. Introduction to Archival Organization and Description. Los Angeles, CA: Getty Information Institute, 1998.

Greisdorf, Howard F., and Brian Clark Connor. Structures of Image Collections from Chauvet-Pont-d'Arc to Flickr. Westport, CT: Libraries Unlimited, 2008.

Hensen, Steven L. Describing Archives: A Content Standard. 2nd ed. Chicago: Society of American Archivists, 2013.

Holmes, Oliver W. (1902-1981). "Archival Arrangement - Five Different Operations at Five Different Levels." The American Archivist 27, no. 1 (1964): 21-42. Accessed November 12, 2014. http://www.jstor.org.

Lanzi, Elisa, and Howard Besser. Introduction to Vocabularies: Enhancing Access to Cultural Heritage Information. Los Angeles, CA: Getty Information Institute, 1998.

Manco, Sara L. "Finding Wolff: Intellectually Arranging the Werner Wolff Fonds at the Ryerson Image Centre," Master's thesis, Ryerson University, 2012. Paper 1264.

"Report of the Sub-committee on Finding Aids Guidelines for the Preparation and Presentation of Finding Aids." International Council on Archives Committee On Descriptive Standards, (January 1, 2001). Accessed November 12, 2014. http://www.icacds.org.uk/eng/findingaids.htm.

Rushworth, Matthew. "Issues In Object-Level Description of Press Photography Collections: Toward A Metadata Standard For Photojournalism," Master's thesis, Ryerson University, 2012. Paper 1518. 